\title{
Use of a Fabry-Perot Resonator at Millimeter Wave Frequencies in the Determination of Thin Film Resistivities
}

Stephen J. Hogan
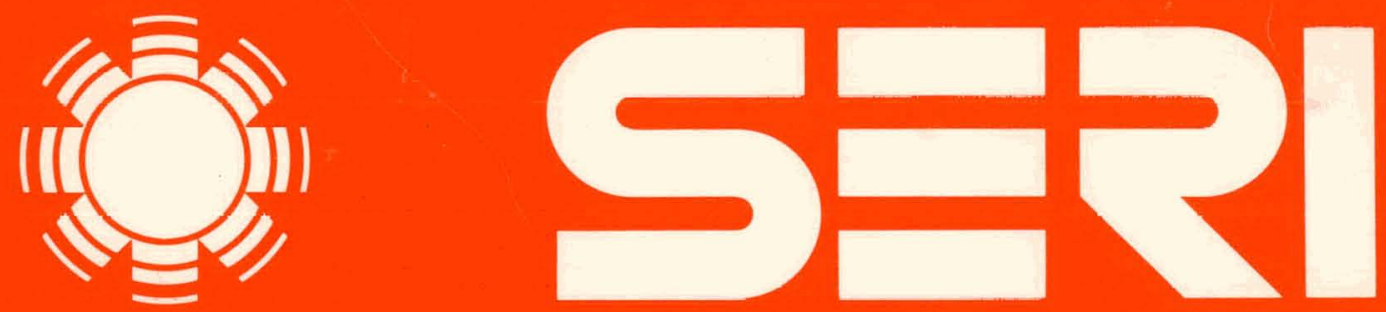

Solar Energy Research Institute A Division of Midwest Research Institute

1536 Cole Boulevard

Golden, Colorado 80401

Operated for the U.S. Department of Energy under Contract No. EG-77-C-01-4042

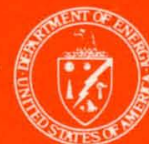




\section{DISCLAIMER}

This report was prepared as an account of work sponsored by an agency of the United States Government. Neither the United States Government nor any agency Thereof, nor any of their employees, makes any warranty, express or implied, or assumes any legal liability or responsibility for the accuracy, completeness, or usefulness of any information, apparatus, product, or process disclosed, or represents that its use would not infringe privately owned rights. Reference herein to any specific commercial product, process, or service by trade name, trademark, manufacturer, or otherwise does not necessarily constitute or imply its endorsement, recommendation, or favoring by the United States Government or any agency thereof. The views and opinions of authors expressed herein do not necessarily state or reflect those of the United States Government or any agency thereof. 


\section{DISCLAIMER}

Portions of this document may be illegible in electronic image products. Images are produced from the best available original document. 
Printed in the United States of America

Available from:

National Technical Information Service

U.S. Department of Commerce

5285 Port Royal Road

Springfield, VA 22161

Price:

Microfiche $\$ 3.00$

Printed Copy $\$ 6.00$

\section{NOTICE}

This report was prepared as an account of work sponsored by the United States Government. Neither the United States nor the United States Department of Energy, nor any of their employees, nor any of their contractors, subcontractors, or their employees, makes any warranty, express or implied, or assumes any legal liability or responsibility for the accuracy, completeness or usefulness of any information, apparatus, product or process disclosed, or represents that its use would not infringe privately owned rights. 
SER I /TR-32-227

UC CATEGORY: UC-63

USE OF A FABRY-PEROT RESONATOR AT MILLIMETER WAVE FREQUENCIES IN THE DETERMINATION OF THIN-FILM RESISTIVITIES

STEPHEN J. HOGAN

AUGUST 1979

PREPARED UNDER IASK NO. 3221.10

\section{Solar Energy Research Institute}

1536 Cole Boulevard

Golden, Colorado 30401

\section{$-\cdot$}

This NOTICE

This report was prepared as an account of work

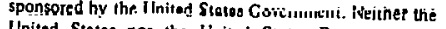
Enited States nor the United States Department of Energy, nor any of their employees, nor any of their contractors, subeontractors, or their employees, makes any wartanty, express ut Implied, ot assumes any legal liability or responsibility for the accuracy, completeness
or usefulness of any information, apparatus, product or usefulness of any information, apparatus, product or process disclosed, or represents
infringe privately owned rights.

A Division of Midwest Research institute -

Prepared for the U.S. Department of Encrgy

Contract No. EG. $77 \cdot \mathrm{C} \cdot 01 \cdot 4042$ 


\section{THIS PAGE}

\section{WAS INTENTIONALLY \\ LEFT BLANK}


SEP

TR -227

FOREWORD

This research project was performed under Contract No. EG-77-C-01-4042, SERI Task 3221.10, and as a thesis was submitted to the Department of Electrical Engineering of the University of Colorado in partial fulfillment of the requirements for the degree of Master of Science. The author is grateful for the support and helpful discussions provided by Sigurd Wagner of SERI and Frank S. Barnes, Russell E. Hayes, William May, and Edward Kuester of the University of Colorado. The Institute of Energy Conversion of the University of Delaware provided the samples of $C d S$ used in the experiments; their cooperation is gratefully acknowledged.

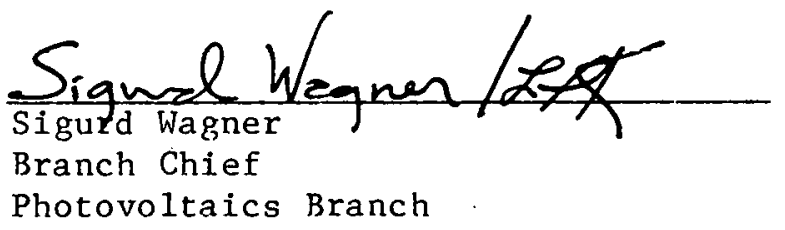

Approved for:

SOLAR ENERGY RESEARCH INSTITUTE

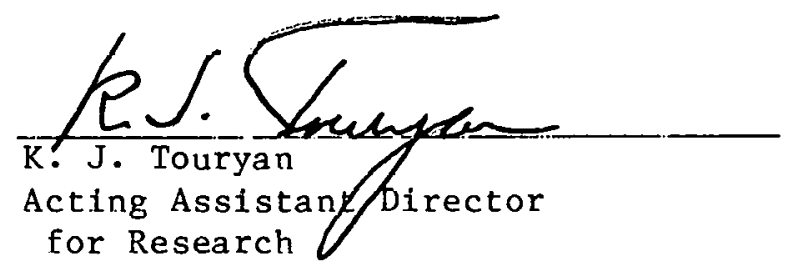

iii 
THIS PAGE

\section{WAS INTENTIONALLY LEFT BLANK}




\begin{abstract}
We have developed a novel contact-free method of measuring resistivity of thin semiconducting films on highly conductive substrates. The material structure studied is commonly encountered in thin-film solar cell development. This report discusses in detail the microwave technique that involves using a semiconfocal Fabry-Perot cavity at a wavelength of $3 \mathrm{~mm}$. The sample consists of a thin film of CdS on a brass substrate and is mounted on the flat reflector of the cavity. Using field perturbation methods, an expression is derived that relates the film resistivity to the cavity quality factor Q. The cavity quality factor is an easily measured parameter and, by comparing measurements of $Q$ with and without the sample mounted, an accurate measure of the resistivity is obtained. Accuracy of measurements and necessary sample constraints are discussed in detail.

Three samples were measured of CdS on brass substrates spanning an order of magnitude in resistivity difference. The results of the method described in this report agree with those of another method that involves current voltage measurement after application of a metallic contact. Unlike the latter method, however, the new technique provides a nondestructive way of measuring the resistivity of semiconductor films on conducting substrates and is amenable to automation.
\end{abstract}


THIS PAGE

WAS INTENTIONALLY

LEFT BLANK 


\section{TABLE OF CONTENTS}

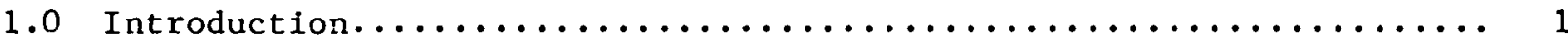

1.1 Resistivity Measurements........................ 1

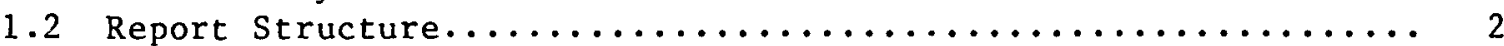

2.0 Literature Review............................... 5

2.1 General Microwave Techniques...................... 5

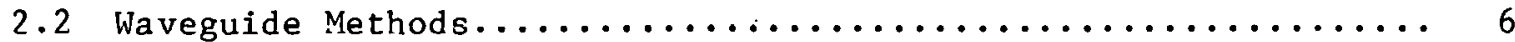

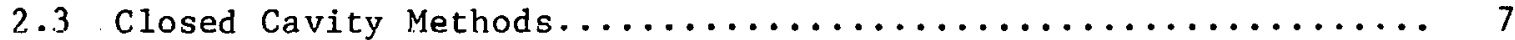

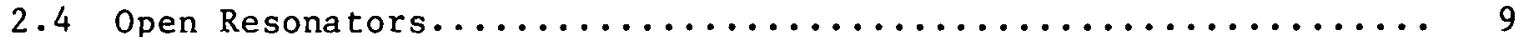

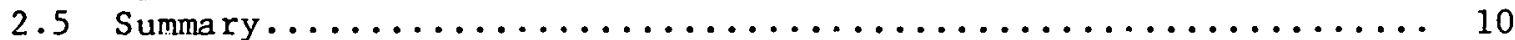

3.0 Open Resonator Characteristics....................... 11

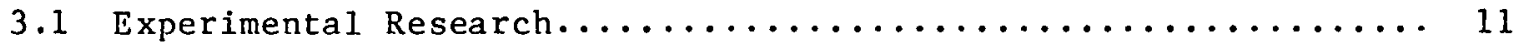

3.2 Spot Size and Effective Resonator Dimensions............... 13

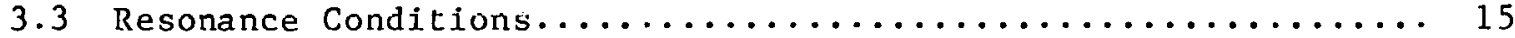

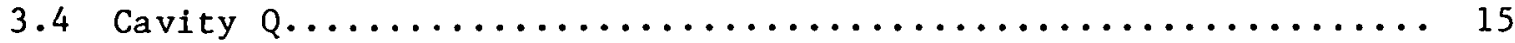

4.0 Sample Perturbation............................. 21

4.1 Nonplanar Cavity Fields......................... 21

4.2 Determination of Cavity $Q$ for Nonplanar Fields........... 25

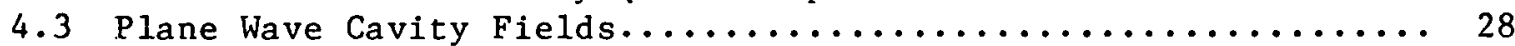

4.4 Determination of Cavity $Q$ for Planar Fields.............. 32

4.5 Derivation of the Expression for Resistivity............ 34

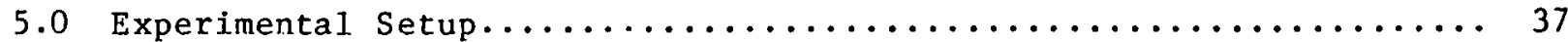

6.0 Experimental Results............................ 43

6.1 Technique for Measurement of $Q \ldots \ldots \ldots \ldots \ldots \ldots \ldots \ldots \ldots \ldots \ldots \ldots$

6.2 Unloaded Cavity $Q$ Measurements...................... 46

6.3 Luaded Cavity $Q$ Measurements........................ 48

6.4 Measured Sample Resistivity........................ 49

7.0 Error Analysis and Limitations....................... 51

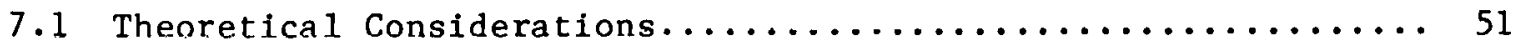

7.2 Physical Limitations......................... 54

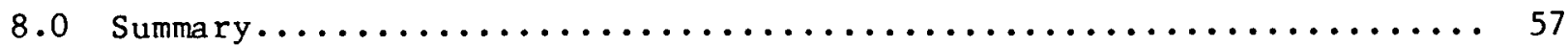

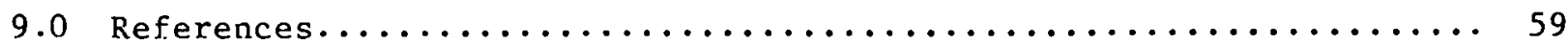


TABLE OF CONTENTS (Concluded)

$\underline{\text { Page }}$

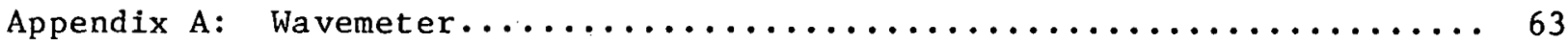

Appendix B: Test System Automation....................... 67

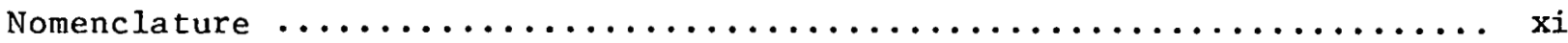




\section{LIST OF FIGURES}

Page

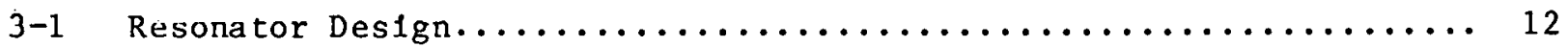

3-2 Effective Resonator.............................. 12

3-3. Effective Constant Phase Spot Size vs. Reflector Spacing......... 14

3-4 Theoretical Plot of Maximum Quality Factor for Nonperturbed

Cavity vs. Wave Mode $q \ldots \ldots \ldots \ldots \ldots \ldots \ldots \ldots \ldots \ldots \ldots \ldots \ldots \ldots$

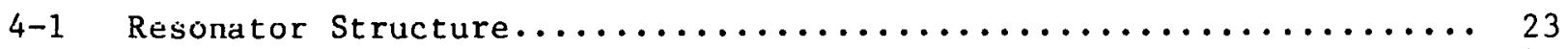

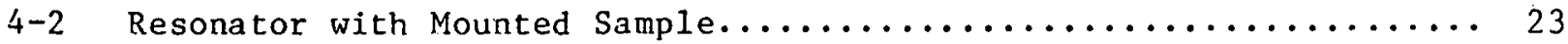

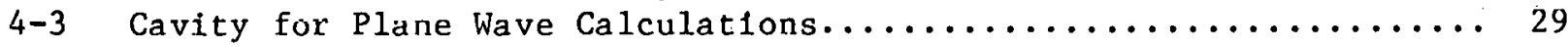

4-4 Cavity with Sample for Plane Wave Calculations................ 29

5-1 Microwave Resistivity Measurement Apparatus............... 38

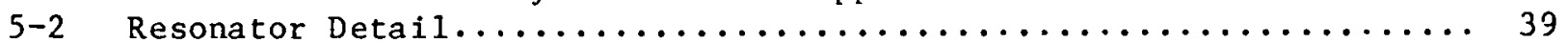

5-3 Photograph of Experimental Setup.................... 41

6-1 Smith Chart Calculation of Half-Power Point.............. 45

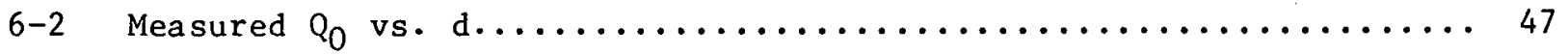

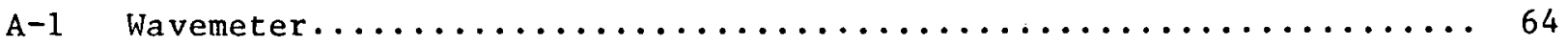

B-1 Suggested Automated Setup......................... 68

B-2 Block Diagram of the Implementation of an Automatic Measurement

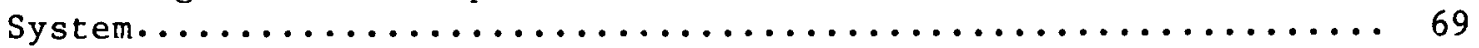

\section{LIST OF TABLES}

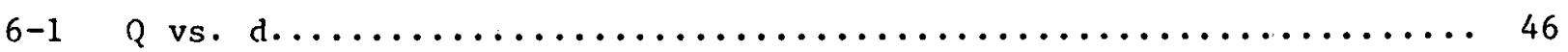

$6-2$ Measured $Q$ Values........................... 49

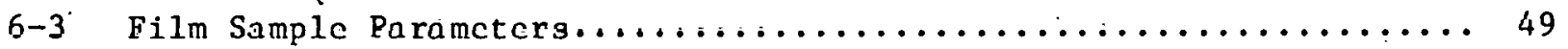

6-4 Sample Resistivity............................. 50

8-1 Film Resitivity Using Two Methods................... 57 
THIS PAGE

WAS INTENTIONALLY

LEFT BLANK 


\section{NOMENCLATURE}

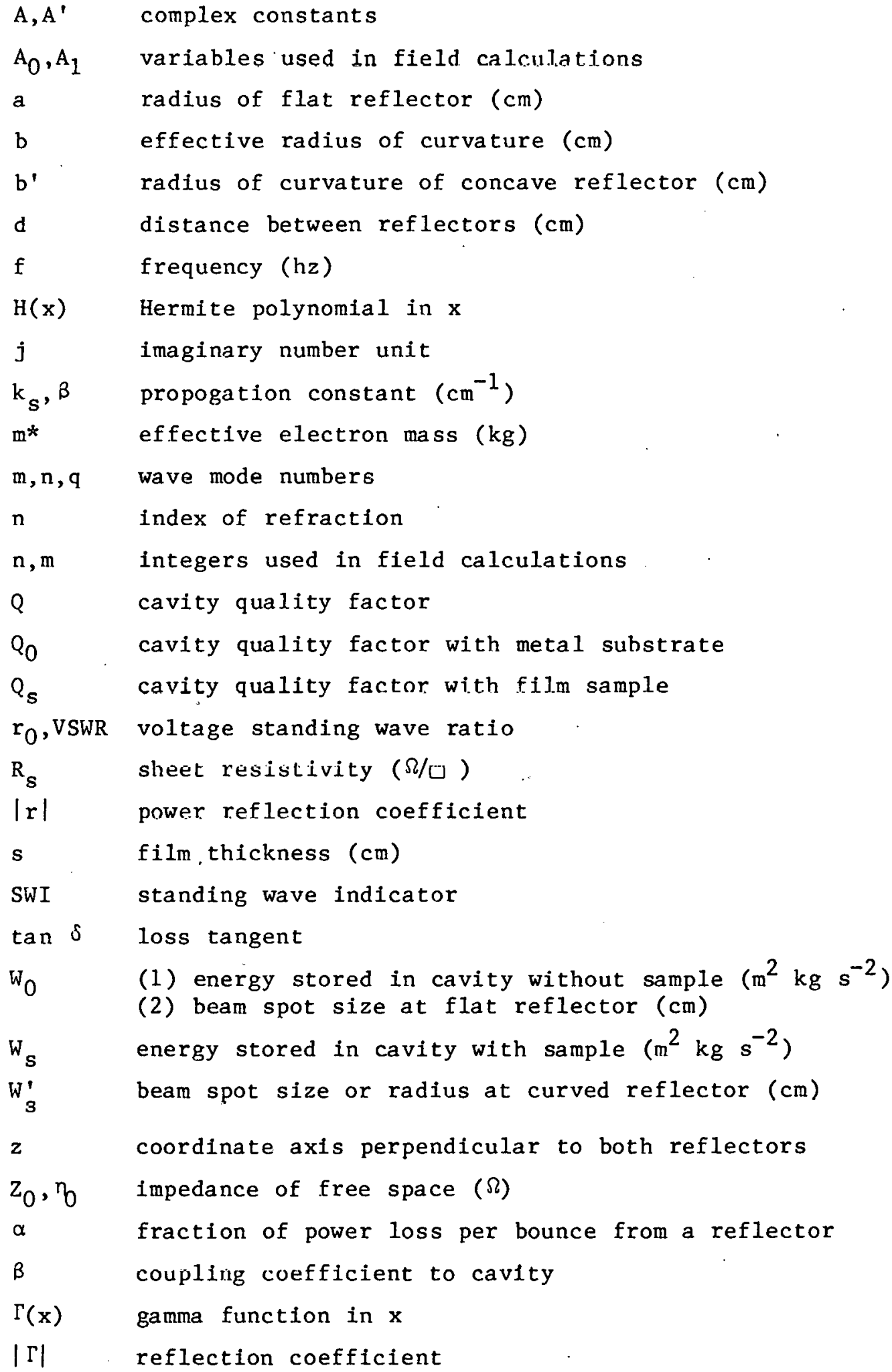


NOMENCLATURE (concluded)

skin depth $(\mathrm{cm})$

dielectric constant of material ( $F / c m$ )

relative dielectric constant wavelength $(\mathrm{cm})$

waveguide cutoff wavelength $(\mathrm{cm})$

(1) permeability of material $(\mathrm{H} / \mathrm{cm})$;

(2) carrier mobility $\left(\mathrm{cm}^{2} / \mathrm{V} \mathrm{s}\right)$ resistivity of material $(\Omega(\mathrm{cm})$ conductivity of material $\left[(\Omega \mathrm{cm})^{-1}\right]$ carrier lifetime (s) susceptibility of material (cg s) angular frequency ( $\mathrm{rad} / \mathrm{s}$ ) 


\section{SECTION 1.0}

\section{INTRODUCTION}

The current projections and past experiences of energy shortages have had farreaching impacts on energy research in the United States. A major program gaining importance in federal research funding and public awareness and support is the examination of solar energy as a viable alternative source of energy. This program has a very wide scope, but of significant interest is the terrestrial application of photovoltalc cells. An active research program is underway at the Solar Energy Research Institute in photovoltaics, whereas the Jet Propulsion Laboratory is manaing a project with the goal of marketing photovoltaic systems installed at $\$ 700$ per $\mathrm{kW}_{\mathrm{pk}}$ by the year 1986 .

There is no unanimous agreement on the particular material technology that could meet even lower cost goals beyond 1986. Important contenders in the quest for economical photovoltaic cells are those that are fabricated using thin fllms of semiconducting compounds. The best understood thin-film cell structure is $\mathrm{CdS}-\mathrm{Cu}_{2} \mathrm{~S}$ [1]: but cells using other compound semiconductors are currently being studied [2,3]. The methods of thin-film deposition also vary, and include vacuum evaporation and chemical deposition methods sprayIng, and thick film application $[4,5]$. In many of the methods and material investigations the semiconducting material is deposited on a conductive substrate. Common substrates range from brass to indium tin oxide on glass. An important parameter that needs characterization is the bulk resistivity of the film on the substrate.

\subsection{RESISTIVITY MEASUREMENTS}

Resistivity and its effect on the operation and efficiency of solar cells has been studied and well documented $[6,7]$. Accurate knowledge of the resistivity of the film is required in thin-film cell $R \& D$ and manufacture. In manufacturing, resistivity measurements serve as an important guide to the process parameters and as an indication of performance of the completed cell. In research, it allows rapid characterization of the effects in modifying the stoichiometric and processing parameters. For example, manufacturers of Cds$\mathrm{Cu}_{2} \mathrm{~S}$ cells are interested in knowing the resistivity of the CdS film deposited on a brass substrate. Knowledge of this value before the deposition of the $\mathrm{Cu}_{2} \mathrm{~S}$ layer provides baseline data for overall cell performance and prevents loss in time and materials resulting from a $\mathrm{Cu}_{2} \mathrm{~S}$ deposition on an inadequate base layer of CdS.

Typically, for materials of a wide range of resistivity, the measurement is made using a four-point probe technique. This method relies on a uniform current through the bulk of the sample and eliminates contact effects. In the case of a thin film on a conducting substrate, the method is not applicable because a conductive layer exists at a distance from the contacts much shorter than the distance between the contacts of the four-point device. As a result, the injected current goes vertically through the material to the substrate, across the substrate of high conductivity, then back through the film to the collection contact. The probes do not sense a voltage drop corresponding to 
the total current running through the bulk of the material. Without knowing the actual current through the bulk, it is impossible to determine the correct value of resistivity. It is possible to run the deposition process with an insulating substrate and then measure the resistivity of this film on the insulator. This method, however, gives no indication of interaction between the film and metal substrate, which could affect the resistivity.

The use of a microwave Fabry-Perot interferometer is an attractive solution to the problem for several reasons. With proper consideration the problem can be solved by utilizing the high conductivity properties of the substrate. The method is contact-free and thereby eliminates possibilities of damage by the contacts on a soft film. It also lends itself to development of a system that theoretically can provide fast measurements in a manufacturing environment. Recent advances in millimeter wave technology have made equipment avallable that is capable of generating very stable, high power fields. Th1s equipment and the improved understanding of detection and cavity construction make it practical to perform a feasibility study.

\subsection{REPORT STRUCTURE}

This report covers three major areas. The first area includes examination of the cavity, past work done in the use of microwave techniques for sample analysis, and the theoretical calculations of these methods. Then the experimental setup is explained in detail and the results of the measured samples are given. Finally, sample limitations imposed by the theory are discussed and the results are summarized. An analysis of test system automation is given in Appendix B.

Section 2.0 discusses previous work using microwave techniques to measure the dielectric constant and loss tangent of materials. Past work has involved the use of many distinct schemes and sample mounts for characterization. Methods as diverse as inserting powder into quartz tubes or accurate milling of spheres of the sample have been used almost exclusively for examining large samples to determine dielectric constants or complex permittivity. The method most frequently used is an examination of the eddy currents induced in a carefully prepared sample. A complete discussion of this and other methods is presented.

The cavity, a semiconfocal open resonator, used in the system developed in this project is described in section 3.0. The theory of the setup is discussed, with focus on cavity characteristics when no sample is present. Parameters such as spot size and the expected cavity quality factor Q are examined to determine properties of the sample that are acceptable. The discussion includes reviews of the relevant literature and the effects of varying approximations. Two theories are formulated in detail: (1) analysis based on the assumption of the fields as plane waves, and (2) the more rigorous ana 1ysis of the fields as prolate spheroidal functions.

Section 4.0 discusses the system when the sample is perturbing the fields. It deals specifically with the formulation of an equation relating the two measured values of cavity $Q$ (i.e., with and without film samples in the cavity) and the resistivity of the film. The analysis is consistent with an analysis 
performed by Culshaw \& Anderson [8], and allows two methods of determining film resistivity relating to the two field approximations.

The setup of the system is described in Section 5.0. A complete listing of system components is included.

Section 6.0 presents discussion of the methods of data collection and the results for different samples of CdS. Variances in the data are analyzed and some practical difficulties are examined.

Section 7.0 is concerned with the limitations imposed on the samples by the assumptions made in the development of the theory. Also examined are the areas where errors in measurement are most apt to be found.

In Section 8.0 the results of this technique are summarized and compared with the results from another technique: employed by an independent outside source. An excellent correlation is shown.

The first of the two appendices discusses the wavemeter used to make the frequency measurements. Appendix B considers the conversion of the laboratoryscale device to an automated version for commercial-scale use. 


\section{SEश**}




\section{SECTION 2.0}

\section{LITERATURE REVIEH}

Microwave techniques were used in the measurement of material parameters before 1950. There was an increase in microwave measurement activities using a variety of approaches in the fifties and sixties. These research activities, however, did not lead to a market development of analytic instruments. It is our opinion that this lack of availability of instruments could be attributed to complexities of final solution expressions and llmitations placed on test samples. However, certain applications of microwave measurement techniques could be made quite attractive.

\subsection{GENERAL MICROMAVE TECHNIQUES}

Several documents provide good tutorials on the use of microwave methods. Culshaw wrote an excellent review of millimeter wave techniques developed through the 1950s [9]. His paper includes analyses of transmission methods, measurement techniques, and total reflection studies; and a discussion of the state-of-the-art instrumentation in 1961. Of particular interest is his discussion of both Michelson and Fabry-Perot interferometers at millimeter wavelengths. His analyses constitute much of the pioneer work in the use of interferometers at these wavelengths. In a subsequent article Bhar summarized microwave techniques in the study of semiconductors [10]. Bhar discussed concisely methods and the theory of conductivity at microwave frequencies. He then described in detail three measurements: (1) a study of the temperature dependence of semiconductor dielectric constant and conductivity, (2) the determination of the infrared absorption coefficient of a semiconductor, and (3) the measurement of minority carrier lifetime. Another paper, by Tremblay and Bolvin, covers the broader area of the concepts of microwave optics [11]. The paper deals with a variety of subjects, including diffraction theory, waveguides, microwave optical instruments, and hardware for millimeter wave techniques. It includes an extensive bibliography of almost 600 references. Other important sources of background information are the numerous books on microwave measurements [12-17]. These books present established techniques and theories of processes.

The literature reviewed in the remainder of this section is divided into three main topics: (1) systems employing waveguide perturbation techniques, (2) methods of material characterization using closed cavities, and (3) the usage of open resonator techniques. All of the methods have certain characteristics in common, but there are subtle differences in basic theory and sample limitations. In general the majority of the articles is chiefly concerned with the dielectric constants of insulating materials. Others discuss the analysis of eddy currents, which places restrictions on sample size and configuration. The techniques described in the open-resonator literature most closely resemble the investigation presented in this report, but varying approximations have been used. 


\subsection{WAVEGUIDE METHODS}

Insertion of the sample into waveguides has been examined extensively, with the most common methods of analysis involving determination of the transmission and/or reflection coefficients. The methods vary in that the sample may partially or completely fill the waveguide, either in a long section or at a termination. Jacobs et al. described an electrodeless measurement of resistivities of semiconductor samples that totally filled the waveguide [1,8]. Single-crystal samples were inserted into the waveguide and the resistivity was determined by a measurement of power transmission through the sample. Correlation with d.c. measurements was good, but the sample was limited to a single-crystal material and waveguide size. Sandus [19] pointed out the 1imitations of comparisons of d.c. resisttivity with microwave resistivity when measurements are made in the mauuer of Jacobo et a1. His objection was that for many semiconductor compounds, the sulfides excluded, the measured conductivity at microwave frequencies is a function of the absorption spectra of the material. The sulfides are excluded because their lowest dispersion frequency lies in the infrared. Another letter by Champlin and Armstrong considered the results of Jacobs et al. and examined the different approximations for completely versus partially-filled waveguldes [20].

Havemann and Davis used a procedure similar to that used by Jacobs et al. in determining the conductivity of thin metal films [21]. They calculated the transmission and reflection coefficients of a metal film inserted in a square waveguide. A restriction of this method was a maximum measurable film thickness of $1050 \AA$ at $10 \mathrm{GHz}$. In a similar experiment, Ramey and Lewis looked also at thin metal films but assumed a total reflection [22]. They contended that even though a film may be less than the calculated skin depth, internal reflection processes will still yield total reflection, and transmission will occur only for a thickness much less than the skin depth. This analysis might either explain certain anomalies observed by Havemann and Davis or totally refute their findlugs. An interecting point raised by Ramey and Lewis is that films which contain relatively high concentrations of gasses display a frequency-dependent conductivity. Th1s characteristic applies to materials deposited at $10^{-5}$ torr or higher. Conductivity was not considered in their paper; instead, optical coefficients were examined. Chaurasia and Voss also examined a thin metal film in a rectangular gulde and calculated the transmission coefficient to determine resistivity [23]. The film was 1imited to less than 100 \& thickness.

Reflection techniques were discussed in several papers. Lindmayer and Kutsko examined thick semiconductor samples (i.e., greater than $50 \mu \mathrm{m}$ thick) that terminated a waveguide [24]. Use of the power reflection coefficient and the voltage standing wave ratio (VSWR) made it possible, with a complex expression, to determine the resistivity. This process required use of a precalibrated table of individual thicknesses and dielectric constants. An added constraint was that the material being tested had to be substantially thicker than the skin depth. A paper by Naber and Snowden [25] extended the analysis of Lindmayer. By analyzing the reflection and VSWR measurements, they were able to make quiescent and transient conductivity measurements. The transient measurements were then related to the photoconductivity process. In a presentation by Champlin et al., a large sample was used to fill a circular $\left(\mathrm{TE}_{01}\right)$ waveguide [26]. Under the assumption of infinite depth of materia1, 
the reflection coefficient was measured using a reflection-coefficient bridge. A large sample depth (compared to skin depth) was required. An interesting analysis of the advantages of this mode over other modes was presented, and the conclusion was that, because sample contact to side walls was not necessary, this mode did not create the contact impedance created by the $\mathrm{TE}_{10}$ mode.

Nag and Roy analyzed samples in a waveguide to determine conductivity and the dielectric constant [27]. The VSWR was measured in a simple arrangement, but a major stipulation was that the sample thickness be a multiple of quarterwavelengths. In subsequent articles, Nag, Roy, and Chatterji gave more detailed analyses of their previous work [28,29]. Retuning by length adjustment for a minimum in power reflection compensated for varying sample thickness. The sample was no longer a sheet, but a slab machined to fit transversely into the waveguide. Careful contacting to side walls was again required, as pointed out by Gunn [30].

The technique initiated by Nag et al. using specially shaped samples has also been popular. Holmes et al. mounted vertically a circular or square semiconductor post in the rectangular waveguide [31]. In their paper the authors presented experimental results, a theoretical analysis, and extensions of the technique to applications for lifetime measurements. Mckinney and Duff also presented a sketchy analysis of rod dimension effects when the rod was inserted into a rectangular waveguide [32]. A paper which combined waveguide and cavity techniques was written by Allerton and Seifert [33]. These authors described two methods of measurement. The first was a reflection measurement of the film terminating a transmission line. Measurement of the ratio of conduction to reflection made it possible to determine resistivity for thick slabs. The second method used a cavity technique of looking at power transmitted through a cavity when a portion of the cavity wall was composed of the material being tested. Without special considerations this method is limited to samples whose thicknesses are substantially greater than their skin depths. Certain steps can be taken to look at thin samples but they require possible material changes.

\subsection{CLOSED CAVITY METHODS}

The majority of cavity techniques described in the literature examined field losses in a sample due to eddy currents. The important restriction of such techniques was that the dimension of the sample affected by the fields needed to be much greater than the skin depth. Thus currents were generated on the surface of the sauple, and by careful dimensional analysis the resistivity was determined.

Champlin and Krongard described a technique of cavity perturbation theory that allowed computation of the resistivity and the dielectric constant [34] Their procedure required insertion of a small sphere of the test material into the cavity. By monitoring the frequency shift and quality factor it was. then possible to determine the eddy currents within the sample and thereby to determine the resistivity of the sample. Low conductivity samples required variations in the analysis using perturbed techniques. The method differed from standard eddy-current methods in that there were no multivalue resi:lts. 
The standard method of using eddy currents was introduced by Linhart et al. [35]. A spherical sample, the radius of which was much greater than the skin depth, was placed at the center of a circular cylindrical cavity excited in the $\mathrm{H}_{011}$ mode. By measuring the change in the quality factor and assuming all losses to be due to surface eddy currents, the authors derived an expression for the resistivity. The authors discussed the shape factors that compensate for nonspherical samples. Kohane and Sirvetz took the spherical sample concept a step further and were able to remove sample size restrictions [36]. The sample was positioned in the cavity where the magnetic field was at a maximum and the electric field was zero. The authors then related the eddy currents induced by the magnetic field to the sample resistivity. Knowing the field intensity at the center of the cavity, they measured the power loss and calculated the resistivity. Owston also demonstrated the use of eddy currents to determine resistivity of thin mecal fllins [37]. The flat filns were mounted in the cavity, and loss of power transmission through the cavity was associated with the eddy currents and hence the resistivity. In addition, the system of probing the sample was analyzed. Kohane also examined a spherical sample in a cavity [38]. The method was again restricted to a sample radius greater than the skin depth. By measuring quality factors and power loss, he was able to determine a variable for the test sample that was a function of the transmission coefficient. Two solutions to the problem could occur, and to eliminate ambiguity a second sample had to be measured. Kohane discussed the effect of measurements over a wide variation of equipment operating temperatures, concluding that careful attention must be paid to the apparatus during testing.

Transmission and reflection measurements used in cavity techniques have been examined. Bichara and Poitevin measured the reflection off thick samples of low resistivity films for many known values of sample thickness and resistivity [39]. Using the curves thus generated, they were able to measure the resistivity of a new sample with known thickness. The calculations were valid only for samples much thicker than the skin depth, hence limiting thin samples to very low values of resistivity. The method was applied to epitaxial layers on thick substrates and gave good results. An analysis by Orgeret and Boucher considered power transmission through a film to determine other factors such as carrier lifetime and surface recombination velocity [40]. In another transmission approach, Danilov et al. developed a method for calculations of semiconductor parameters [41]. Their article is lacking in detail and the conclusions are sketchy. However, Akhinanaev et al. [42] briefly described an instrument based on the work of Danilov et a1.: a power transmission apparatus that is designed to measure resistivity.

Roussy and Felden developed a novel method of determining the permittivity of powders [43]. The powders were contained in a quartz tube which was pressurized and inserted in a cavity. By examining transmission properties it was possible to correlate the permittivity with their measurements. Covington and Ray examined films on insulating substrates [44]. Curves were generated for sample thickness and dielectric constant to determine the resistivity. The authors presented excellent theory on film power transmission and reflection; however, the underlying theory again had its origin in eddy-current losses.

Another cavity approach was concerned with bimodal resonant cavities. In this approach the incident microwave field excited a mode in the sample, which in 
turn excited currents in the sample. Portis explained how these currents then excited a second mode that was coupled to the detection system [45]. High resistivity samples were most suitable for this method, and the sensitivity of measurements was improved over previous methods. Portis briefly described the use of this technique to determine the mobility of photocarriers in CdS. Pethig and South extended this technique to Hall mobility measurements [46], and Eley and Pethig discussed applications of the method to biological samples [47]. Recently Watanabe et al. discussed the microwave conductivity of semiconductors due to an eddy-current loss [48]. The method is restricted to thick samples and so is limited to measurements of samples whose resistivity is between $5 \times 10^{-4}$ and $6 \times 10^{-3} \mathrm{M} \Omega$.

\subsection{OPEN RESONATORS}

The use of an open resonator is the method most applicable to the theory developed in this report. The basic theory of this technique dates back to the late fifties, when the Boulder Laboratories of the National Bureau of Standards (NBS) were actively researching millimeter wave techniques. Culshaw published several papers, and much of his original work is cited in Section 3.0 on cavity characteristics. Culshaw proposed the use of two planar surfaces to set up a Fabry-Perot interferometer [9]. His concept involved placIng the sample in the middle of the cavity and determining the dielectric constant and the resistivity of the sample. The work was limited to samples of multiple quarter-wavelength thicknesses. The measurements, similar to those described in this report, used the quality factors of loaded versus unloaded cavities. Their method was described in greater detail in a subsequent paper by Culshaw and Anderson [8]. A length retuning technique was the principle behind the theory, but the results of work on frequency retuning were also presented. The measurement of the length or frequency required to retune to resonance was used in the calculation of material parameters.

Cullen and Yu used a confocal resonator with the sample centered between the reflector surfaces [49]. In this technique of permittivity measurement, the conditions of resonance were determined using spherical surfaces and Gaussian beam theory. Compared to other methods, these led to quite good values of measured dielectric and loss tangents. The samples were large compared to normal thin films and could not exhibit great reflectivity. Cullen and Yu gave an excellent summary of other research and of the error analysis techniques for their system.

Degenford and Coleman were perhaps the first to demonstrate accurate measurements of dielectric constants [50]. Their experiment used a confocal fabryPerot resonator in which the sample was mounted in the center of the cavity. The unusual feature of their setup was that the sample was tilted by some known angle. When the dielectric sheet was tilted in this manner, the reflected beam was removed from the cavity. This greatly simplified the resultant field and amplitude calculations. The formula for determination of the dielectric constant was thus reduced to a simple linear relation involving only the ratio of the sample thickness to the mirror movement required to restore resonance. Values obtained from this method were good but not sufficiently accurate. In subsequent work by Degenford, modifications to the theory were made to determine the loss tangent of the sample [51]. The loss 
tangent expression became a linear but complex relation of mirror distance, sample thickness, $Q$, and retuning distance. Use of this expression may be the most viable method of microwave measurements of dielectric materials.

In other open resonator work, Breeden and Sheppard obtained many of the same theoretical answers by measuring sample characteristics in a Michelson-type interferometer [52]. By using mirror retuning for the sample which was inserted in the resonator, they determined the dielectric constant and the loss tangent. A restriction of their technique was that it required very accurate and large sample thickness. Bandpass filtering in data processing also presented a problem. Breeden and Langley later proposed mounting the dielectric material in a semiconfocal Fabry-Perot resonator, but they did not give details on the apparatus and only gave measurements of a single sample [53]. Interestingly, they preferred frequency lelunlug uvei mirror rctuning duc to the higher accuracy of frequency measurements.

More recently, Cook et al. compared cavity/waveguide versus open-resonator measurements of permittivity and loss tangent of a dielectric sample [.54]. The open resonator was in a hemispherical configuration, and the calculations reduced to measurements of $Q$, the sample retuning distance, and the separation distance between the mirrors. The cavity measurement was made by inserting the sample in the end of a helical waveguide. Measurements of the dielectric constant and resistivity of dielectric materials by the two methods compared we11.

Anderson presented a method of dielectric constant and loss tangent measurement for thick samples in both confocal and semiconfocal Fabry-Perot resonators [55]. His analysis was quite thorough in its investigation of fields present in the resonator. It is used as a reference several times in Section 4.0 when fields are required. The principal disadvantage of his theory is that for the calculation of parameters a computer numerical integration is necessary for each sample of differing thickness or dielectric constant.

\subsection{SUMMARY}

There is much information in the literature concerning microwave measurement techniques. Problems exist, however, in most methods for measurement of thin films on metal substrates. The waveguide techniques generally require careful consideration of material conductivity to sidewalls for proper mode continuation. They usually require either thick blocks that fill the waveguides or thin samples which transmit power through the material. Cavity measurements generally require thick samples (i.e., much greater than the skin depth) in specific shapes.. When thick samples are not necessary, transmission of power through the sample is required, thereby 1gnoring eddy currents. Both requirements limit the use of cavity measurement techniques. Open resonator structures have the least restrictive requirements for thin films. For this reason, such a structure was investigated. in the project described in the remainder of this report. 
It has long been realized that application of optical techniques at millimeter wavelengths would benefit the understanding of new microwave devices. In 1959 Culshaw suggested possible reflector configurations for a microwave FabryPerot interferometer [56]. Using flat composite reflectors with quarterwavelength dielectric sheets spaced by air gaps, he demonstrated use of the open cavity with input and output norns for radiation and detection and examined the effects of the number of plates, and their reflection, on cavity reasonance conditions. By use of transmission line theory he developed a matrix calculation of the fields and induced currents. His emphasis was on analysis of reflector design variations and the effect those variations had on transmission properties. The following year Culshaw published a much more detailed analysis of the plane-mirrored interferometer [57]. In this particular design he demonstrated $Q$ values of 100,000 for power reflection coefficients of 0.999. Without considering diffraction effects, he was able to make wavelength measurements with accuracies of $0.04 \%$. He also suggested uses of the setup for possible measurements of material properties, specifically of loss tangent and dielectric constant. His principal results were still related to fringe widths and reflector designs. In further considerations he cited possibilities of the use of the resonator structure as a maser resonator [58]. (This was also examined by Temple [59].). Culshaw went into more detail on the fields within the cavity as well as the theoretical Q. He also briefly discussed several other reflector surfaces, including planar, focused spherical, biconical spherical, and hemispherical biconical surfaces. He summarized this work and discussed millimeter techniques in an excellent tutorial article [9], in which he covered at length all aspects of resonator design for planar reflectors, as well as the theoretical Q's to be obtained. He also reviewed material properties at microwave frequencies, and transmission and reflection considerations. In the same year two related papers were published, one by Fox and Li [60] and the other by Boyd and Gordon [61].

\subsection{EXPERIMENTAL RESEARCH}

Our resonator design is shown in Fig. 3-1. It is a semiconfocal Fabry-Perot resonator, modified in such a manner that the requirement of $d=b^{\prime} / 2$ is relaxed. The value $b^{\prime}$ is the radius of curvature and fixed at $1 \mathrm{~m}$. The advantages of the use of a near semiconfocal configuration are manifold. Such a configuration provides a convenient sample mounting surface. It has been shown that alignment of the mirrors is not as critical as it is for planemirrnre. surfares. The reduction in spot size, as compared to that of the plane reflector configuration, limits the losses due to diffraction, thereby allowing higher $Q$ for the resonator (although it limits the losses only half as much as does the fully confocal resonator). Indeed, Boyd and Gordon showed that as long as $d \ll b^{\prime}$ the problems of diffraction of the field out of the resonator are minimal [61]. All assumptions are based on the requirement which is easily satisfied in this case of a wavelength of about $3.2 \mathrm{~mm}$. The losses within the resonator are therefore limited to losses within the metal reflectors and the losses of the film when it is inserted. 


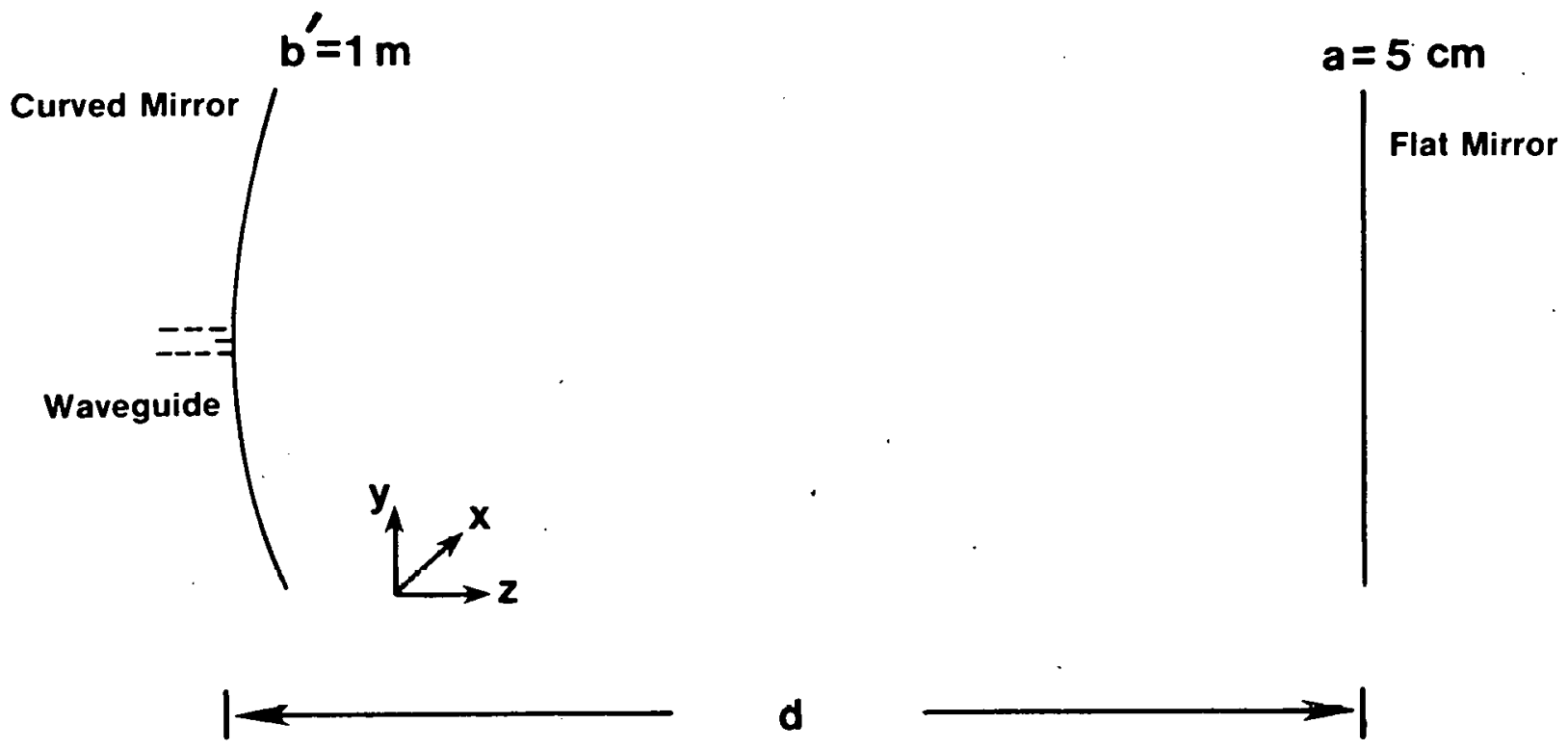

Figure 3-1. Resonator Design

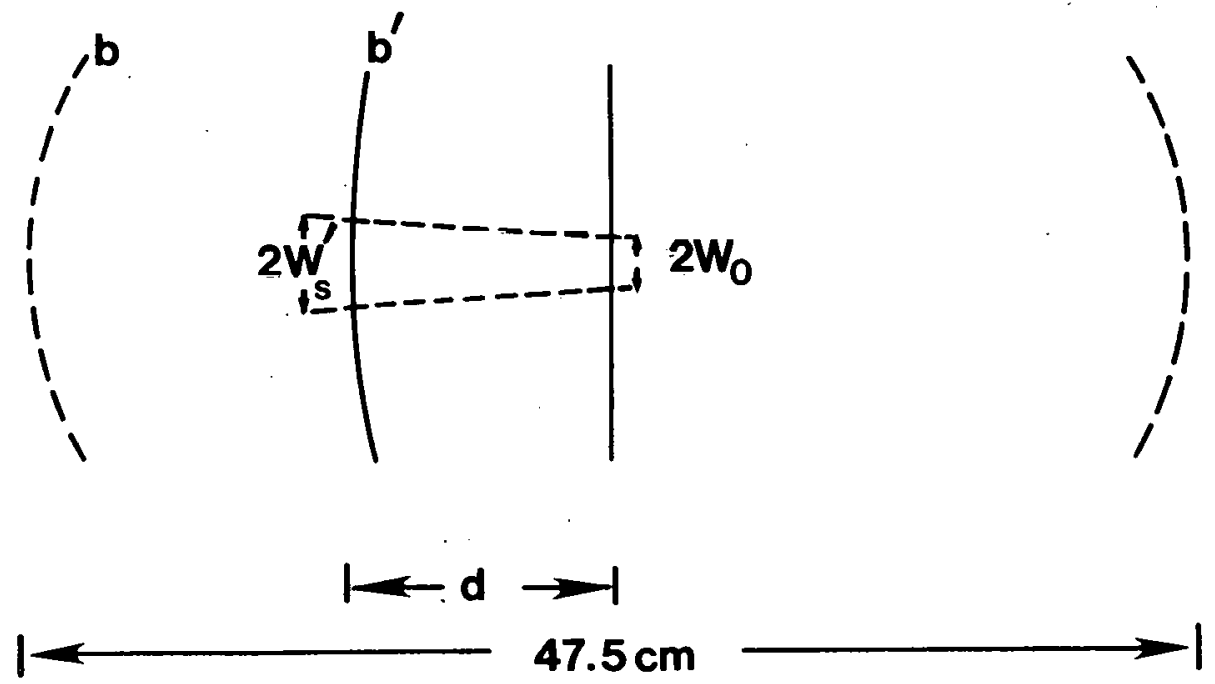

Figure 3-2. Effective Resonator 


\subsection{SPOT SIZE AND EFFECTIVE RESONATOR DIMENSIONS}

An important concern is the determination of constant phase surfaces and spot size. The spot size is defined as the radius of the beam when its field intensity reaches a value of $1 / \mathrm{e}$ of the intensity along the propagation axis. Boyd and Gordon determined that a constant phase surface of radius $b^{\prime}$ and spacing $2 d$ can be approximated as a confocal resonator of radius $b$, as illustrated in Fig. 3-2, with the following relationship:

$$
(2 d)^{2}-4 d b^{\prime}+b^{2}=0 \text {. }
$$

Therefore, for a typical value of $d=6 \mathrm{~cm}$, we find $\mathrm{b}=47.5 \mathrm{~cm}$. It is then possible to use this value to determine from the Boyd and Gordon calculations the spot size $W_{0}$ at the flat plate and the effective constant phase spot size $W_{S}^{\prime}$ at the curved surface:

$$
w_{0}=\left(\frac{b \lambda}{2 \pi}\right)^{1 / 2}
$$

and

$$
W_{s}^{\prime}=w_{0}\left(1+\frac{(2 d)^{2}}{b^{2}}\right)^{1 / 2}
$$

This yields $W_{0}=1.55 \mathrm{~cm}$ and $W_{s}^{\prime}=1.6 \mathrm{~cm}$. Thus the spot size varies very slowly along the resonator axis.'

Another method presented by Boyd and Gordon for the nonconfocal condition gives

$$
w_{s}^{\prime}=\left(\frac{2 d \lambda}{\pi}\right)^{1 / 2}\left[\frac{4 d}{b^{\prime}}-\left(\frac{2 d}{b^{\prime}}\right)^{2}\right]^{-1 / 4} .
$$

Figure 3-3 plots $W^{\prime}$ versus values of $d$ that are of interest in this experiment. Once it is verified that spot size is small compared to resonator dimensions, it becomes possible to examine the conditions of resonance and field modes present in the cavity. 


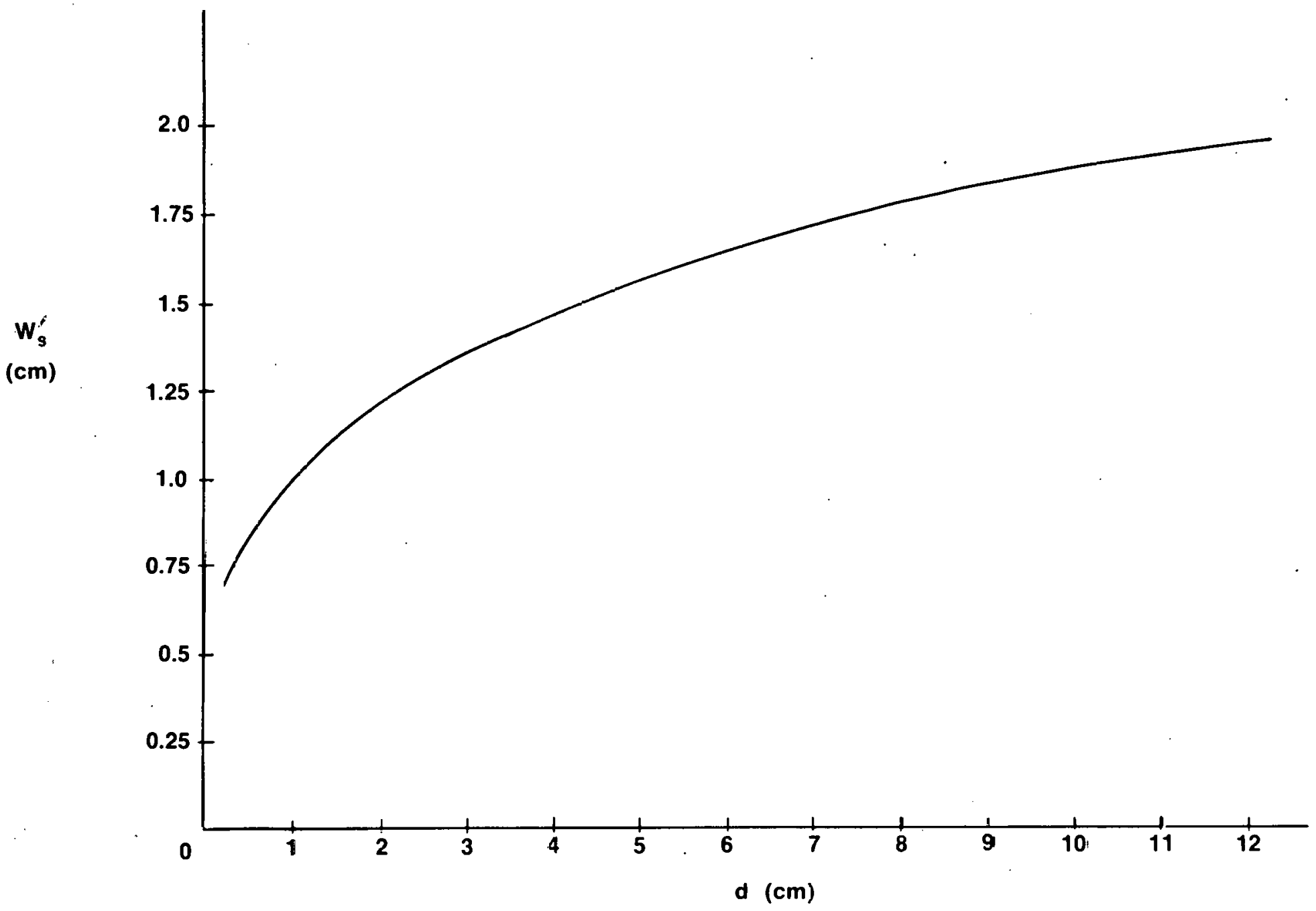

Figure 3-3. Effective Constant Phase Spot Size vs. Reflector Spacing 


\subsection{RESONANCE CONDITIONS}

Sheppard and Rothamel suggested guidelines for Fabry-Perot cavity design resulting from examination of the confocal resonator [62]. They defined for the mode design the condition

$$
\frac{a^{2}}{b^{\prime} \lambda} \simeq 1
$$

to assure operation in the TEM ${ }_{\text {oog }}$ mode. For our situation this value is 0.78 , indicating potential difficulties in operation. Boyd and Kogelnik examined the semiconfocal resonator and found the conditions of resonance to be

$$
\frac{2 d}{\lambda}=q+\frac{1}{2 \pi}(1+m+n) \cos ^{-1}\left(1-\frac{d}{b^{\prime}}\right)
$$

for resonance in the $\mathrm{TEM}_{\mathrm{mnq}}$ mode [63]. Making the assumption of operation in the TEM ${ }_{\text {ooq }}$ mode we obtain

$$
\lambda_{\text {res }}=\frac{2 d}{g+(1 / 2 \pi) \cos ^{-1}\left(1-d / b^{\prime}\right)} .
$$

For values of $d$ obtainable in the setup, this equation yields values of $q$ ranging from 3 at $d=0.5 \mathrm{~cm}$ to 74 at $d=12 \mathrm{~cm}$. Temple pointed out the importance of a higher $q$ value to insure damping of the diffractive effects of the higher order transverse modes, $i . e ., m, n \neq 0$ [59].

\subsection{CAVITY Q}

A theoretical maximum $Q_{0}$ for the unloaded cavity has been calculated using two different techniques. The first, introduced by Culshaw [9], yields

$$
Q_{0}=\frac{\lambda}{\Delta \lambda}=\frac{n \pi}{\left(1-|\mathbf{n}|^{2}\right)}
$$

This result is derived using an approximation of plane waves within the cavity, a subject which is further analyzed later in this report. The planar assumption is based on the fields

$$
E_{y}=2 j F_{0} \sin \left(n \pi_{z} / 2 d\right)
$$


and

$$
\mathrm{Z}_{0} \mathrm{H}_{\mathrm{x}}=2 \mathrm{E}_{0} \cos \left(\mathrm{n} \pi_{z} / 2 \mathrm{~d}\right)
$$

The energy stored is

$$
P=\frac{1}{2} \varepsilon \operatorname{Re} \int_{0}^{d} E E^{*} d z
$$

and the power lost is

$$
P_{L}=(\omega \mu / 2 \sigma)^{1 / 2}|H|^{2},
$$

with $Q$ defined as

$$
Q \equiv \frac{\text { (1) } \times \text { energy stored }}{\text { power lost }} \text {. }
$$

The power reflection coefficient of the metal, $|r|^{2}$, is defined as

$$
|r|^{2}=1-(8 \kappa \omega / \sigma)^{1 / 2}
$$

Substituting Eq. 3-13 into Eq. 3-8 gives

$$
Q_{0}=n \pi(8 \varepsilon \omega / \sigma)^{-1 / \%}
$$

when $n$ is given as the values of $q$ that were determined per Eq. 3-7. We then can solve for the expected values of $Q$ for the design resonator with gold end plates. For the gold plates we find [64]

$$
\begin{gathered}
\sigma_{\text {gold }}=1 / \rho_{g}=\left(2.44 \times 10^{-6} \Omega \mathrm{cm}\right)^{-1}, \\
\varepsilon_{g} \simeq \varepsilon_{0}=8.85 \times 10^{-14} \mathrm{~F} / \mathrm{cm}, \\
\omega=2 \pi \mathrm{f}=2 \pi(92.4 \mathrm{GHz}) \mathrm{rad} / \mathrm{sec} .
\end{gathered}
$$


When these values for $\sigma, \varepsilon$, and $w$ are substituted in Eq. 3-14, we find

$$
Q_{0}=n \pi /\left(1.001 \times 10^{-3}\right)
$$

and therefore

$$
Q_{0} \simeq q \pi \times 10^{3}
$$

Figure 3-4 gives the expected values of $Q$ for increases of both $q$ and the associated values of $d$.

Boyd and Gordon also considered the theoretical value of $Q_{0}$, but they were not restrictive regarding the fields present in the resonator [61]. Their solution gave an unloaded $Q_{0}$ of

$$
Q_{0}=\frac{\pi d}{\alpha \lambda}
$$

where $\alpha$ is the fractional power loss per reflection and represents a sum of both diffractive and reflective losses. Noting that

$$
\mathrm{q}=\mathrm{d} / \lambda,
$$

we obtain

$$
Q_{0}=\pi_{q}(\alpha)^{-1}
$$

If diffractive losses are neglected, $\alpha$ may be solved as follows for a plane wave reflecting from a plane conducting surface of surface recictivity $R_{S} \Omega / \square[65]$ :

$$
\alpha=\frac{4 R}{\eta_{0}} \text {, }
$$

where $\eta_{0}$ is the wave impedance of free space. The value of $\eta_{0}$ is

$$
n_{0}=\left(\frac{\mu_{0}}{\varepsilon_{0}}\right)^{1 / 2}=377 \Omega \text {. }
$$

The surface resistivity is defined as the resistance of material, $\rho$, divided by the skin depth $\delta$ :

$$
R_{s}=\rho / \delta
$$




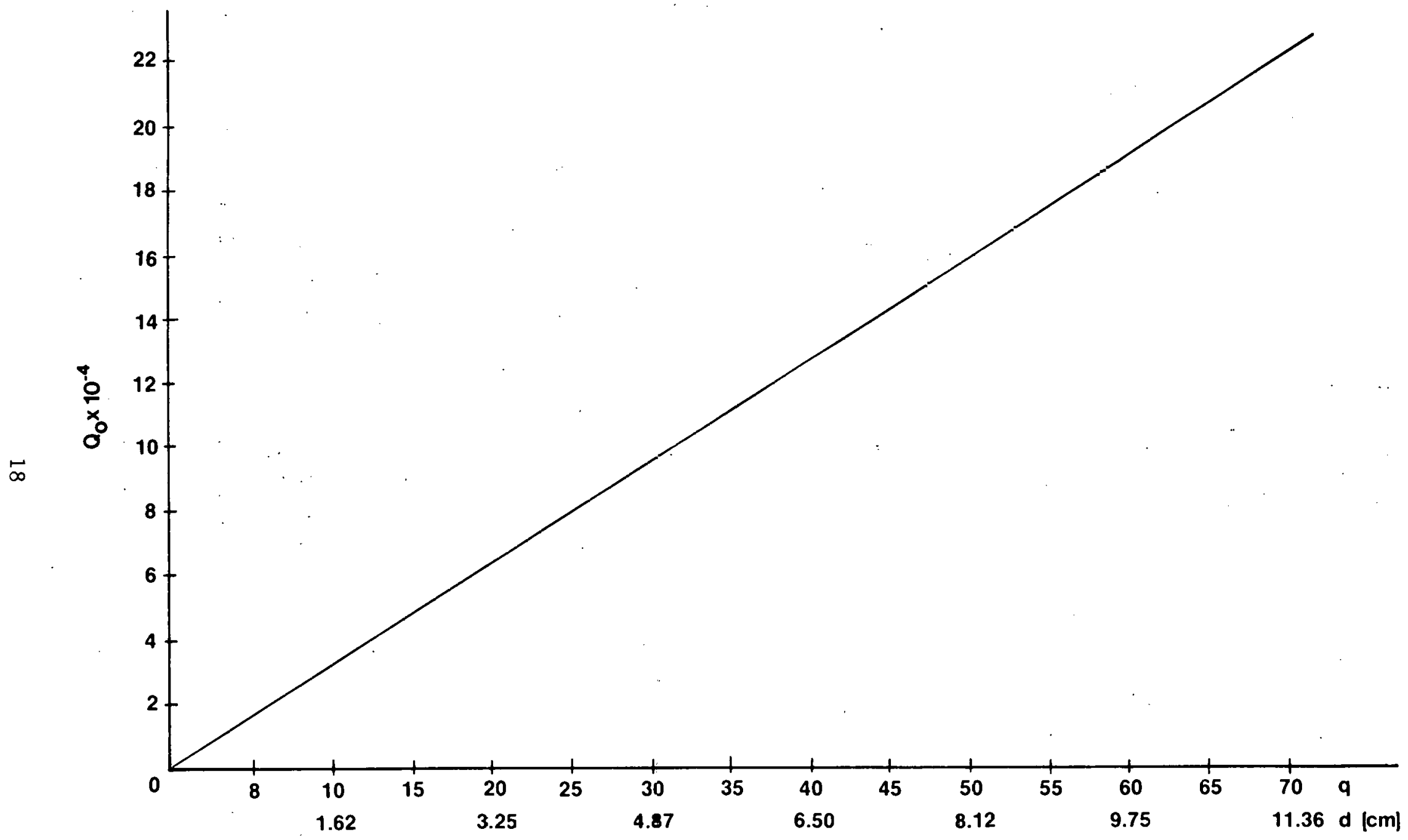

Figure 3-4. Theoretical Plot of Maximum Quality Factor for Nonperturbed Cavity vs. Wave Mode $q$ 
The skin depth is defined as the depth to which a field has penetrated a material when the field amplitude has decreased to $1 / e$ of the entrance amplitude. It is defined as

$$
\delta=\frac{1}{2 \pi}\left(\frac{4 \pi \rho \lambda}{\mu c}\right)^{1 / 2}
$$

and is a useful quantity in the analysis given later in this report.

Solving again for the value of $\Omega_{0}$ at a wavelength of $\lambda=0.325 \mathrm{~cm}$, where

$$
\begin{gathered}
\rho=2.44 \times 10^{-6} \Omega \mathrm{cm}, \\
\mu_{g}=\mu_{0}\left(1+x_{g}\right) H / c m \equiv \text { permeability, }
\end{gathered}
$$

and

$$
x_{g}=-28 \times 10^{-6} \mathrm{cgs} \equiv \text { susceptibility, }
$$

so that

$$
\mu_{g} \simeq \mu_{0}=4 \pi \times 10^{-9} \mathrm{H} / \mathrm{cm}
$$

gives a value of

$$
\delta=2.58 \times 10^{-5} \mathrm{~cm}
$$

As expected, the fields penetrate the gold to a very shallow depth of 0.258 $\mu_{m}$, which gives

$$
R_{S}=9.43 \times 10^{-2} \Omega / 0
$$

for a solution of $\alpha=1.001 \times 10^{-3}$.

In verification of Eq. (3-15) we then find

$$
Q_{0} \simeq q \pi \times 10^{3}
$$

In summary, it is possible to determine the conditions of resonance for the semiconfocal Fabry-Perot resonator. Spot size is calculated to ensure that 
the resonator dimensions are much greater than the fields and the incident wavelength. If these criteria are met, the losses due to diffraction can be neglected. Under this assumption it is then possible to calculate the unloaded $Q_{0}$. This calculation involves reflector material parameters and the distance between reflectors. An important question is the accuracy of the assumption of plane-wave fields within the resonator, and this subject is discussed in Section 4.0. 
$\ddot{i n}$

\title{
SECTION 4.0
}

\author{
SAMPLE PERTURBATION
}

The primary problem involved with an analysis of sample effect in the resonator is the determination of the propagation of the fields in the interferometer. In the early work by Culshaw [9] and also the report from Culshaw and Anderson [8], the fields were assumed to be planar. In a later paper by Culshaw, the fields for several reflector configurations were expressed as integral equations [66]. Fox and $\mathrm{Li}$ [60] also considered different resonator structures, and, using Huygens-Kirchhoff diffraction theory, they were able to develop integral equations for the fields. They expressed the field distribution as a function of the number of bounces between reflectors and found that for typical cavity geometries the fields reached a steady-state condition. They performed numerical solutions for the eigenvalues and eigenfunctions (the field distribution). Boyd and Gordon [61] confined their analysis to the confocal resonator and found that the integral equation could be solved in closed form by expressing the eigenfunctions and eigenvalues in terms of the angular and radial wave functions in prolate spheroidal coordinates. Solutions for this approximation involve a complex expression of a Hermite Polynominal series. Lotsch [67] likewise used prolate spheroidal coordinates and obtained a solution for rectangular flat reflectors similar to the solution found by Boyd and Gordon. He also used the principle of a Huygen envelope construction with Young's principle of interference. In later work by Kogelnik and Li, the fields were assumed to take on a Gaussian distribution around the axis of propagation [68]. In this analysis the eigenfunctions or field distributions were approximated as either Hermite-Gaussian or LaguerreGaussian functions.

We decided to approach the problem using two theoretical analyses. The first involved a solution in which a Hermite-Gaussian field distribution was assumed. The second analysis involved approximations of the fields as plane waves expressed by the sine and cosine functions. We expected that the latter approximation would yield a more simplified result, and we hoped that experimental data would verify this approach as a viable technique. The analysis of the first approximation follows the techniques of Anderson [55], while the latter follows the approach of Culshaw and Anderson.

\subsection{NONPLANAR CAVITY FIELDS}

Boyd and Gordon derived the integral equation for the fields, obtaining the following expression for the fields in an unloaded cavity [61]: 


$$
\begin{aligned}
\frac{E(x, y, z)}{E_{0}}= & \left(\frac{2}{1+\xi^{2}}\right)^{1 / 2} \frac{\Gamma\left(\frac{m}{2}+1\right) \Gamma\left(\frac{n}{2}+1\right)}{\Gamma(m+1) \Gamma(n+1)} H_{m}\left[x\left(\frac{2}{1+\xi^{2}}\right)^{1 / 2}\right] H_{n}\left[Y\left(\frac{2}{1+\xi^{2}}\right)^{1 / 2}\right] \\
& \times \exp \left\{-\left[k w^{2} / b\left(1+\xi^{2}\right)\right]-j\left[\left(k \frac{b}{2}-(1+\xi)+\frac{\xi w^{2}}{\left(1+\xi^{2}\right) b^{2}}\right)\right.\right. \\
& \left.\left.-(1+m+n)\left(\frac{\pi}{2}-\phi\right)-\omega t\right]\right\} .
\end{aligned}
$$

Figure 4-1 shows the resonator structure, where the terms used in Eq. (4-1) are defined as:

$$
\begin{aligned}
& \xi=\frac{2 z}{b}, \text { a normalized factor of length; } \\
& z \equiv \text { direction along the propagation axis; } \\
& b \equiv \text { radius of curvature; } \\
& a \equiv \text { radius of mirror; } \\
& c=\frac{a^{2} k}{b}, \text { a constant; } \\
& k=2 \pi / \lambda, \text { the propagation constant; } \\
& w^{2}=x^{2}+y^{2}, \text { radius of beam; } \\
& X=x \sqrt{c / a}, \text { a nornalized length; } \\
& Y=y \sqrt{c / a}, \text { a normalized length; } \\
& \phi=\tan ^{-1}(1-\xi / 1+\xi) .
\end{aligned}
$$

In the case we fonsidered, we had $a=5 \mathrm{~cm}, \mathrm{~b}=100 \mathrm{~cm}, \mathrm{k}=2 \pi / 0.325=19.33$ $\mathrm{cm}^{-1}$, and $c=\frac{a^{2} \mathrm{k}}{b}=4.8$. Boyd and Gordon demonstrated graphically that this value of $c$ ensures that the cavity fields may be approximated as angular prolate spheroidal functions. This particular value of $c$ also guarantees that the axial fields off axis are very small, and if we consider the TEM mng modes, the value of $m=n=0$ is a good assumption. Thus Eq. (4-1) can be simplified to

$$
\begin{aligned}
& \frac{E}{\mathrm{E}_{0}}=\left(\frac{2}{1+\xi^{2}}\right)^{1 / 2} \exp \left\{-\left[k w^{2} / \mathrm{b}\left(1+\xi^{2}\right)\right]-j\left[\left(k \frac{b}{2}(1+\xi)+\frac{\xi}{1+\xi^{2}} \frac{w^{2}}{b^{2}}\right)\right.\right. \\
& \left.\left.-\left(\frac{\pi}{2}-\phi\right)-\omega_{t}\right]\right\}
\end{aligned}
$$

Boyd and Gordon showed that Eq. (4-8) represents spherical surfaces that are of constant phase at the rounded reflector and change gradually to planar constant phase surfaces at the flat reflector. 

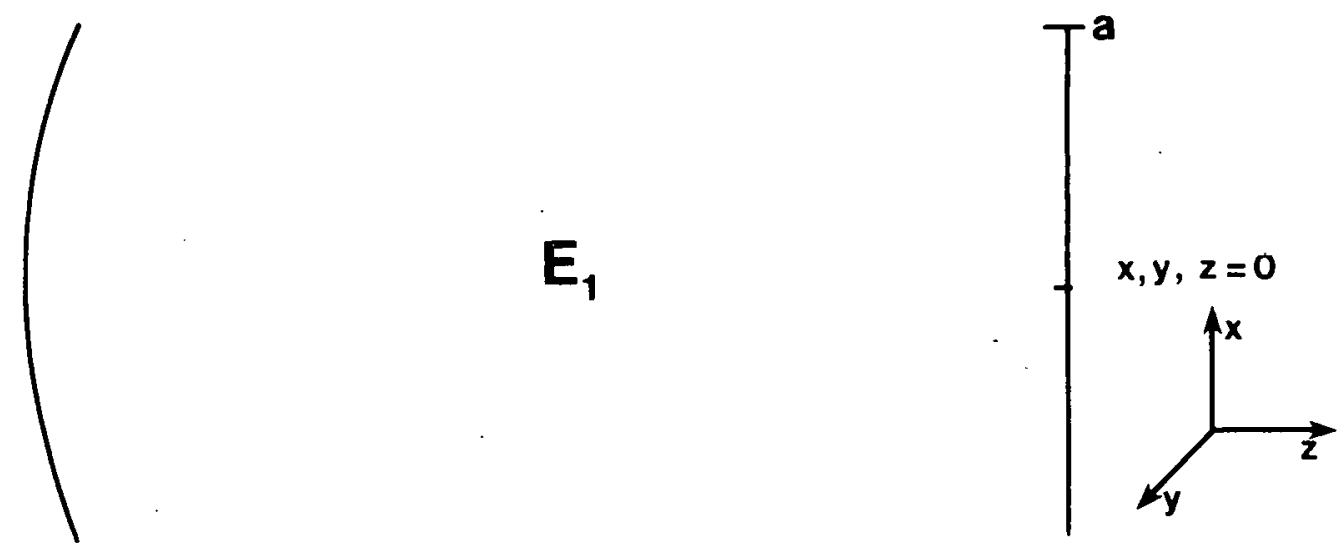

Figure 4-1. Resonator Structure
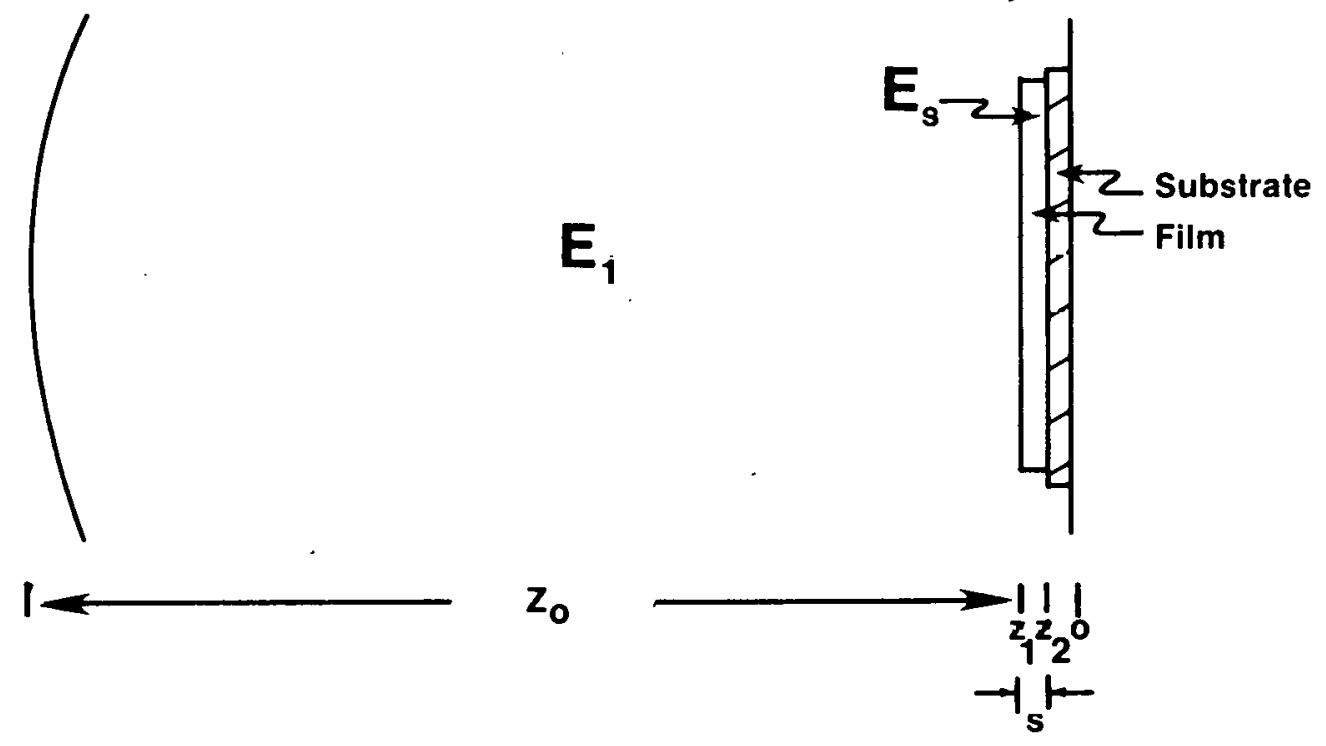

Figure 4-2. Resonator With Mounted Sample 
A further simplification occurs in Eq. (4-8) if we consider that the field is nearly planar at the flat reflector, and, therefore, that letting $w=0$ is appropriate. (Later in the analysis, when a film sample is inserted, the sample must be thin and of generally even characteristics such that the phase change through the sample is uniform over the entire sample.) The approximation of $w=0$ yields

$$
\frac{E}{E_{0}}=\left(\frac{2}{1+\xi^{2}}\right)^{1 / 2} \exp \left\{-j\left[\frac{k b}{2}(1-\xi)-\left(\frac{\pi}{2}-\phi^{\prime}\right)-\omega t\right]\right\},
$$

where

$$
\phi^{\prime}=\tan ^{-1}\left(\frac{1+\xi}{1-\xi}\right)
$$

This represents a wave traveling to the left with a form expressed by

$$
\left(\frac{2}{1+\xi^{2}}\right)^{1 / 2} \exp \left\{-j\left[\frac{k b}{2}(1-\xi)-\left(\frac{\pi}{2}-\phi^{\prime}\right)-\omega t\right]\right\},
$$

and a wave traveling to the right is expressed by

$$
\left(\frac{2}{1+\xi^{2}}\right)^{1 / 2} \cdot \exp \left\{j\left[\frac{k b}{2}(\xi-1)+\phi+\omega t\right]\right\} .
$$

The superimposition of the two waves as the field in the resonator yields

$$
\begin{aligned}
E=\left(\frac{2}{1+\xi^{2}}\right)^{1 / 2} \exp [j(\omega t-k b / 2)] & \left\{A j \exp \left[-j\left(\frac{k b}{2} \xi+\phi\right)\right],\right. \\
& \left.+A^{\prime} \exp \left[j\left(\frac{k b}{2} \xi+\phi\right)\right]\right\},
\end{aligned}
$$

where $A$ and $A^{\prime}$ are complex constants to be determined later in this analysis.

Figure 4-2 represents the resonator with the sample mounted. Designating the fields in the free space as $E_{1}$ and those in the sample as $E_{s}$ makes it possible to write

$$
\begin{aligned}
E_{1}=\left(\frac{2}{1+\xi^{2}}\right)^{1 / 2} \exp \left(-j \frac{k b}{2}\right)\left\{A_{1} j \exp \left[-j\left(\frac{k b}{2} \xi+\phi\right)\right]\right. \\
\left.+A_{1}^{\prime} \exp \left[j\left(\frac{k b}{2} \xi+\phi\right)\right]\right\} \exp \left(j \omega_{c} t\right)
\end{aligned}
$$


and

$$
\begin{aligned}
E_{s}=\left(\frac{2}{1+\xi^{2}}\right)^{1 / 2} \exp \left(-\frac{k_{s} b}{2}\right)\left\{A_{s} j \exp \left[-j\left(\frac{k_{s}^{b}}{2} \xi+\phi\right)\right]\right. \\
\left.+A_{s}^{\prime} \exp \left[j\left(\frac{k_{s}^{b}}{2} \xi+\phi\right)\right]\right\} \exp \left(j \omega_{c} t\right),
\end{aligned}
$$

where $k_{s}$ is the propagation constant in the material. Solutions can be obtained by imposing the following boundary conditions on the fields and tangential components:

$$
\begin{aligned}
& E_{1}=0 \text { at } z=z_{0}, \\
& E_{s}=0 \text { at } z=z_{2}, \\
& \partial E_{1}=\frac{\partial E}{\partial} \text { at } z=z_{1} .
\end{aligned}
$$

The solutions are quite involved, and an analysis similar to that found in Ref. 56 will yield the following condition for resonance:

$$
\tan \left(\frac{k}{2} d-\phi^{\prime}\right)=-\frac{1}{n} \cot \left(\frac{k s}{2} s-\phi^{\prime}\right),
$$

where the sample thickness is assumed to be much less than $d$. Note that $n$ is the index of refraction; i.e.,

$$
\mathrm{n}=\sqrt{\mathrm{k}^{\prime}},
$$

where

$$
\kappa_{C}^{\prime}=\frac{\varepsilon_{C}}{\varepsilon_{0}}=\frac{\varepsilon^{\prime}}{\varepsilon_{0}}-j \frac{\varepsilon^{\prime \prime}}{\varepsilon}=k^{\prime}-j k^{\prime \prime},
$$

so that

$$
\kappa^{\prime}=\frac{\varepsilon^{\prime}}{\varepsilon_{0}}
$$

\section{4-2 DETERMINATION OF CAVITY Q FOR NONPLANAR FIELDS}

The calculation of $Q$ can be made by again defining $Q_{S}$ as the $Q$ of the cavity with sample:

$$
Q_{S} \equiv \omega \frac{\text { average energy stored }}{\text { average power lost }} \text {. }
$$

The power losses may be divided into the following categories: 


$$
\begin{aligned}
\text { Ohmic losses in reflectors } \equiv \mathrm{L}_{\mathrm{M}}, \\
\text { Diffraction losses } \equiv \mathrm{L}_{\mathrm{D}} \\
\text { Loss in sample }=\sigma \int_{\xi_{1}}^{\dot{\xi}_{2}} \int_{0}^{\mathrm{a}} \mathrm{E} \mathrm{s}^{\bullet} \mathrm{E}_{\mathrm{s}}^{*} \mathrm{dw} \mathrm{d} \xi \cdot \quad(4-20)
\end{aligned}
$$

The loss in sample may also be defined as

$$
\omega \varepsilon \tan \delta \int_{\xi_{1}}^{\xi_{2}} \int_{0}^{a} E_{s} \cdot E_{s}^{*} d w d \xi
$$

since the loss tangent is defined as

$$
\tan \delta=\sigma / \omega \varepsilon
$$

for nondielectric materials. The average energy stored may be expressed as

$$
\text { Energy Stored }=\varepsilon_{0} \int_{\xi_{0}}^{\xi} 1 \int_{0}^{a} E_{1} \bullet E_{1}^{*} d w d \xi+\varepsilon \int_{\xi_{1}}^{\xi_{2}} \int_{0}^{a} E_{s} \cdot E_{s}^{*} d w d \xi \text {. }
$$

Combining the above equations, we obtain

$$
Q_{S}=\frac{\omega\left[\varepsilon_{0} \int_{\xi_{0}}^{\xi_{1}} \int_{0}^{a} E_{1} \cdot E_{1}^{*} d w d \xi+\varepsilon \int_{\xi_{1}}^{\xi_{2}} \int_{0}^{a} E_{s} \cdot E_{s}^{*} d w d \xi\right]}{\omega \varepsilon \tan \delta \int_{\xi_{1}}^{\xi_{2}} \int_{0}^{a} E_{s} \cdot E_{s}^{*} d w d \xi+L_{M}+L_{D}} \cdot(4-24)
$$

When we divide by $\varepsilon_{0}$, Eq. $(4-24)$ becomes

$$
Q_{s}=\frac{\omega\left[\int_{\xi_{0}}^{\xi_{1}} \int_{0}^{a} E_{1} \bullet E_{1}^{*} d w d \xi+\kappa^{\prime} \int_{\xi_{1}}^{\xi_{2}} \int_{0}^{a} E_{s} \cdot E_{s}^{*} d w d \xi\right]}{\omega K^{\prime} \tan \delta \int_{\xi_{1}}^{\xi_{2}} \int_{0}^{a} E_{s} \cdot E_{s}^{*} d w d \xi+L_{M}+L_{D}} .
$$

Defining the top term as $W$ and 1nverting Eq. (4-25) gives

$$
\frac{1}{Q_{S}}=\frac{\omega K^{\prime} \tan \delta \int_{\xi_{1}}^{\xi_{2}} \int_{0}^{a} E_{s} \cdot E_{s}^{*} d w d \xi}{\omega W}+\frac{L_{M}+L_{D}}{\omega W} .
$$

We define the following terms: 


$$
\begin{gathered}
Q_{S^{\prime}}^{-1}=\frac{\omega K^{\prime} \tan \delta \int_{\xi_{1}}^{\xi_{2}} \int_{0}^{a} E_{S} \cdot E_{S^{*}} d w d \xi}{\omega W}, \\
Q_{0^{\prime}}^{-1}=\frac{L_{M}+L_{D}}{\omega W},
\end{gathered}
$$

and

$$
\psi=\frac{1}{\kappa^{\prime}} \frac{\int_{\xi_{0}}^{\xi_{1}} \int_{0}^{a} E_{1} \cdot E_{1}^{*} d w d \xi}{\int_{\xi_{1}}^{\xi_{2}} \int_{0}^{a} E_{s} \cdot E_{s}^{*} d w d \xi} .
$$

If the resonator without a sample is examined, $Q_{0}$ may be expressed as

$$
\mathrm{Q}_{0}=\frac{\omega \varepsilon_{0} \int_{\xi_{0}}^{\varepsilon_{1}} \int_{0}^{a} E_{1} \cdot \mathrm{E}_{1}^{*} \mathrm{dw} \mathrm{d} \xi}{\mathrm{L}_{M}+\mathrm{L}_{\mathrm{D}}} .
$$

It is assumed in the above expression that insertion of a sample does not affect the diffraction or reflector losses and that the sample is thin compared to the resonator reflector spacing. The combination of Eqs. (4-30), (4-29), and (4-28) yields:

$$
Q_{0}^{\prime}=Q_{0}\left(1+\frac{1}{\psi}\right)
$$

In a similar manner it is possible to express

$$
Q_{s^{\prime}}^{-1}=\frac{\tan \delta}{\psi+1}
$$

Rewriting Eq. (4-26) gives

$$
\frac{1}{Q_{s}}=\frac{1}{Q_{s^{\prime}}}+\frac{1}{Q_{0^{\prime}}}
$$

or

$$
\frac{1}{Q_{s}}=\frac{\tan \delta}{\psi+1}+\frac{1}{Q_{0}\left(1+\frac{1}{\psi}\right)}
$$

or

$$
\frac{1}{Q_{S}}=\frac{\tan \delta}{\psi+1}+\frac{1}{Q_{0}\left(1+\frac{1}{\psi}\right)}
$$

from Eqs. (4-31) and (4-32).

Solving $\mathrm{Eq} \cdot(4-34)$ for $\tan \delta$ gives. 


$$
\tan \delta=\frac{\psi+1}{Q_{s}}-\frac{\psi}{Q_{0}},
$$

which yields for $\rho$ from Eq. (4-22):

$$
\rho=\frac{1}{\omega \varepsilon}\left(\frac{\psi+1}{Q_{s}}-\frac{\psi}{Q_{0}}\right)^{-1} \text {. }
$$

In an experimental setup, $Q_{0}$ and $Q_{S}$ are measured, a value of $\psi$ determined from Eq. (4-29), and the value of $\rho$ determined. The problem in this technique is that the determination of $\psi$ involves numerical integration techniques and is troublesome. Also, it is necessary to perform this calculation for every sample of differing thickness or varying dielectric constant. This is a burdensome but feasible method with computerized instrumentation.

\subsection{PLANE haVE CAVITY FIELUS}

The analysis of the fields for the resonator under plane wave assumptions may next be determined. Figures $4-3$ and $4-4$ show the resonator with pertinent information; the sample is mounted in Fig. 4-4. From Ref. 48 it is possible to. describe the fields in region 0 , from $z=0$ to $z=z_{1}$, as

$$
E_{0}=2 A_{0} \sin B_{z} \text {, }
$$

and

$$
\mathrm{Z}_{0} \mathrm{H}_{0}=-j 2 \mathrm{~A}_{0} \cos \mathrm{B}_{Z} \text {, }
$$

where again $B$ is the propagation constant equal to $2 \pi / \lambda$.

In region 1 , from $z=z_{1}$ to $z=z_{2}$, the fields are given by

$$
E_{1}=2 A_{1} \sin \left(B_{1} s^{\prime}+\psi\right) \text {, }
$$

and

$$
\mathrm{Z}_{1} \mathrm{H}_{1}=-j 2 \mathrm{~A}_{1} \cos \left(\beta_{1} \mathbf{s}^{\prime}+\psi\right),
$$

where

$$
s^{\prime}=z-z_{1}
$$

The following boundary conditions are imposed:

$$
E_{0}(0)=0 ; \quad E_{1}\left(z_{2}\right)=0 \text {. }
$$

The tangential components at the interface are continuous:

$$
E_{0}\left(z_{1}\right)=E_{1}\left(s^{\prime}=0\right) ; H_{0}\left(z_{1}\right)=H_{1}\left(s^{\prime}=0\right) \text {. }
$$

These boundary conditions imply that the substrate material is several skin depths thick, and thus the substrate effectively terminates the field at the interface of the film and substrate, i.e., $E_{1}\left(z_{2}\right)=0$. With the boundary con- 


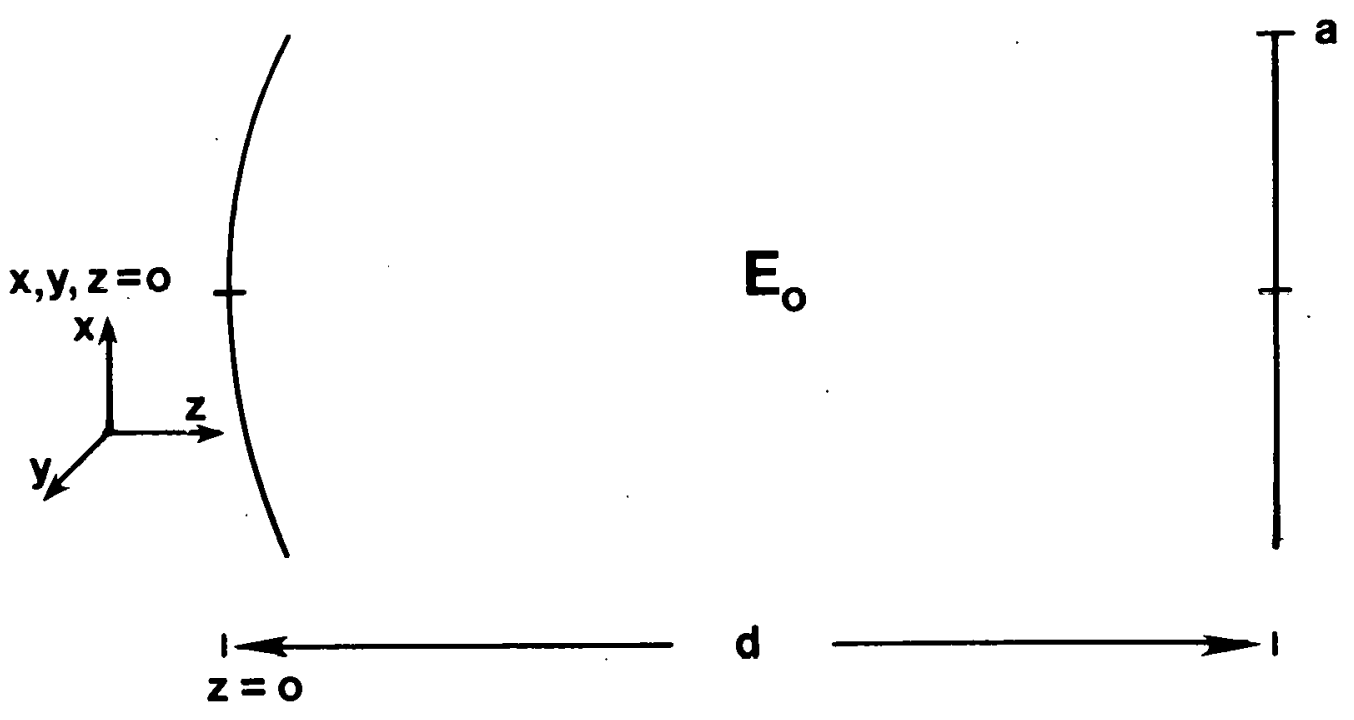

Figure 4-3. Cavity for Plane Wave Calculations
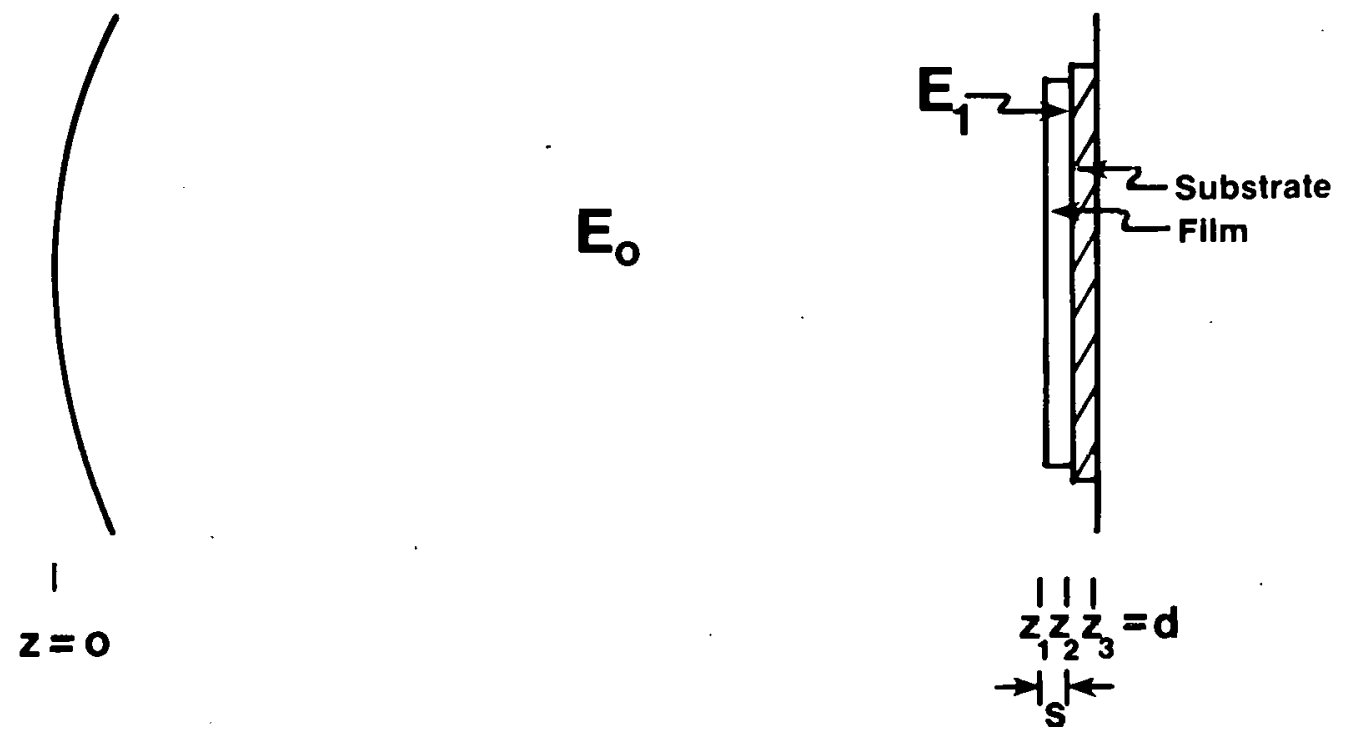

Figure 4-4. Cavity with Sample for Plane Wave Calculations 
ditions it is possible to solve for the variables $A_{1}$ and $\psi$ in terms of $A_{0}$. This is done by first combining Eqs. (4-37) and (4-39) with the appropriate boundary condition to yield

$$
\sin \psi=\frac{A_{0}}{A_{1}} \sin \beta_{z_{1}} \text {. }
$$

Next, combining Eqs. $(4-38)$ and $(4-40)$ with the boundary conditions gives

$$
A_{1}=\frac{z_{1}}{z_{0}} A_{0} \frac{\cos \beta_{z}}{\cos \psi} \text {. }
$$

The substitution $n=\frac{z_{0}}{z_{1}}=\left(\frac{\varepsilon^{\prime}}{\varepsilon_{0}}\right)^{1 / 2}$ is made to obtain

$$
A_{1}=n^{-1} A_{0} \frac{\cos B_{2}}{\cos \psi} \text {, }
$$

or

$$
\cos \psi=\frac{A_{0}}{A_{1}} n^{-1} \cos B_{z_{1}}
$$

Dividing Eq. (4-45) into Eq. (4-42) yields

$$
\frac{\sin \psi}{\cos \psi}=\tan \psi=n \frac{\sin \beta_{z_{1}}}{\cos \beta_{2}}=n \tan \beta_{z_{1}}
$$

or

$$
\psi=\tan ^{-1}\left(n \tan B_{z}\right),
$$

which is one variable. Solution of $A_{1}$ comes from squaring Eq. (4-42):

$$
\sin ^{2} \psi=\frac{A_{0}^{2}}{A_{1}^{2}} \sin ^{2} B_{2}=1-\cos ^{2} \psi \text {. }
$$

Using Eq. (4-45) for cos $\psi$ gives

$$
1=\frac{A_{0}^{2}}{A_{1}^{2}} \sin ^{2} B_{z}+\frac{A_{0}^{2}}{A_{1}^{2}} n^{-2} \cos ^{2} B_{z},
$$

so that

$$
A_{1}=A_{0}\left(\sin ^{2} B z_{1}+n^{-2} \cos B z_{1}\right)^{1 / 2}
$$


The condition of $E_{1}=0$ at $z=z_{2}\left(s^{\prime}=s\right)$ may be inserted into Eq. (4-39) to yield

$$
0=2 A_{1} \sin \left(B_{s}+\psi\right),
$$

so that

Expanding Eq. (4-49) yields

$$
\sin \left(\beta_{S}+\psi\right)=0
$$

$$
\text { oin } B_{\varepsilon} \cos \psi+\operatorname{rns} \beta_{s} \sin \psi=0 \text {, }
$$

so that

$$
\tan \beta_{s}=-\tan \psi
$$

and, by Eq. (4-46),

$$
\tan \beta_{s}=-n \tan \beta_{z_{1}}
$$

Together with the relationship given in Eq. (4-52), this represents a condition of resonance. For resonance a node occurs at $z=z_{2}$, or

$$
\tan \left(\beta_{s}+\psi\right)=0 \text {, }
$$

or

$$
\sin \beta_{s} \cos \psi+\sin \psi \cos \beta_{s}=0
$$

Using Eqs. (4-42) and (4-45) gives

$$
\sin B_{s}\left(\frac{A_{0}}{A_{1}} n^{-1} \cos B_{z_{1}}\right)+\left(\frac{A_{0}}{A_{1}} \sin B_{2}\right)\left(\cos B_{s}\right)=0
$$

or

$$
n^{-1} \cos \beta_{2} \sin \beta_{s}+\cos \beta_{s} \sin \beta_{z_{1}}=0 \text {, }
$$

or

$$
n^{-1} \cos B_{z_{1}}+\sin B_{z_{1}} \cot B_{s}=0 .
$$

Thus we find

$$
\mathrm{n}^{-1}+\tan B z_{1} \cot \beta s=0,
$$

which is another condition for resonance. 


\subsection{DETERMINATION OF CAVITY Q FOR PLANAR FIELDS}

The calculation of $Q$ proceeds in the same manner as the previous determination of $Q . \quad Q$ is redefined

$$
Q=\omega \frac{\text { energy stored }}{\text { power lost }}
$$

or, for the unloaded cavity,

$$
Q_{0}=\frac{\omega W_{S}}{P_{L}+P_{D}} \text {, }
$$

where

$$
\begin{aligned}
& \mathrm{W}_{\mathrm{S}}=\frac{1}{2} \varepsilon_{0} \int_{0}^{\mathrm{z}} 1 \mathrm{E}_{0} \cdot \mathrm{E}_{0}^{*} \mathrm{dz} \equiv \text { energy stored, } \\
& \mathrm{P}_{\mathrm{L}}=\frac{1}{2} \mathrm{R}_{\mathrm{T}} \int \mathrm{H}_{0} \cdot \mathrm{H}_{0}^{*} \mathrm{dA} \equiv \text { power lost in reflection, } \\
& \mathrm{P}_{\mathrm{D}} \equiv \text { power lost due to diffraction } .
\end{aligned}
$$

By use of Eqs. (4-37) and (4-38) the integrals may be evaluated:

$$
\begin{gathered}
W_{s}=\frac{1}{2} \varepsilon_{0} \int_{0}^{z} 1 A_{0}^{2} \sin ^{2} B_{z} d z, \\
W_{s}=2 \varepsilon_{0} A_{0}^{2} \int_{0}^{z} 1 \sin ^{2} B_{z} d z, \\
W_{s}=2 A_{0}^{2} \varepsilon_{0} \int_{0}^{z} 1 \frac{1}{2}(1-\cos 2 B z) d z .
\end{gathered}
$$

Continuing the integral evaluation yields

$$
W_{s}=\varepsilon_{0} A_{0}^{2}\left(z_{1}-\frac{1}{2 B} \sin 2 B_{z_{1}}\right)
$$

For resonance, we also have a node at $z_{1} ; i \cdot e \cdot$,

$$
\mathrm{m} \lambda=z_{1} .
$$

$\beta$ equals $2 \pi / \lambda$, so

$$
2 B_{z_{1}}=\frac{4 \pi}{\lambda} \quad z_{1},
$$

or 


$$
2 \beta_{z_{1}}=4 \mathrm{~m} \pi \text {, }
$$

where $\mathrm{m}$ is an integer. Under this condition, Eq. (4-59) is written as

$$
W_{s}=\varepsilon_{0} A_{0}^{2} z_{1} \text {, }
$$

where $z_{1}=d$, the distance between reflectors; i.e.,

$$
W_{s}=\varepsilon_{0} A_{0}^{2} d
$$

By a similar analysis, the power lost is

$$
\mathrm{P}_{\mathrm{L}}+\mathrm{P}_{\mathrm{D}}=\frac{1}{2} \mathrm{R}_{\mathrm{T}} \int_{0}^{\mathrm{z} 1} \cos ^{2} \beta_{\mathrm{Z}} \mathrm{dz}+\mathrm{P}_{\mathrm{D}} .
$$

Solution of the integral yields

$$
\text { Power Lost }=4 \mathrm{MA}_{0}^{2}+\mathrm{P}_{\mathrm{D}} \text {, }
$$

where

$$
M=\frac{R_{T}}{z_{0}^{2}} .
$$

Combining Eqs. (4-61) and (4-62), we find

$$
Q_{0}=\frac{\omega\left(\varepsilon_{0} d\right)}{4 M+P_{s}},
$$

where

$$
\mathrm{P}_{\mathrm{S}}-\mathrm{P}_{\mathrm{D}} / \mathrm{A}_{0}^{2} \text {. }
$$

The addition of the film introduces the following components to the expression. of Q:

$$
Q_{\mathrm{S}}=\frac{\omega\left(\left(\varepsilon_{0} / 2\right) \int_{0}^{z_{1}} \mathrm{E}_{0} \cdot \mathrm{E}_{0}^{*} \mathrm{dz}+\left(\varepsilon^{\prime} / 2\right) \int_{z_{1}}^{z_{2}} \mathrm{E}_{1} \cdot \mathrm{E}_{1}^{*} \mathrm{~d} z\right)}{\left(\omega \varepsilon^{\prime \prime} / 2\right) \int_{z_{1}}^{z_{2}} \mathrm{E}_{1} \cdot \mathrm{E}_{1}^{*} \mathrm{~d} z+{ }^{1} \overline{2} \mathrm{R}_{\mathrm{T}} \int \mathrm{H}_{0} \mathrm{H}_{0}^{*} \mathrm{dA}+\mathrm{P}_{\mathrm{D}}^{\prime}}
$$

If we again assume that when the film is added the losses due to diffraction are not different from the losses involved in the unloaded case, we find

$$
P_{D}^{\prime} \simeq P_{D}
$$


Under the assumption of a thin film, and thus a field that is not substantially changed while passing through the sample, Eq. (4-65) can be solved to yield:

$$
Q_{s}=\frac{\omega\left[\varepsilon_{0} z_{1}+\varepsilon^{\prime} s\left(\sin ^{2} B_{z_{1}}+n^{-2} \cos ^{2} \beta_{z_{1}}\right)\right]}{\omega \varepsilon^{\prime \prime} s\left(\sin ^{2} \beta_{z_{1}}+\mathrm{n}^{-2} \cos ^{2} B_{z_{1}}\right)+4 M+P_{s}} .
$$

But again for a thin film and resonance, we may say for resonance that

$$
B_{z_{1}}=m \pi
$$

Therefore Eq. $(4-66)$ becomes

$$
Q_{s}=\frac{\omega\left(\varepsilon_{0} z_{1}+\varepsilon^{\prime} \operatorname{sn}^{-2}\right)}{\omega \varepsilon^{\prime \prime} \operatorname{sn}^{-2}+4 M+P} .
$$

Substituting $\frac{\varepsilon_{0}}{\varepsilon^{\prime}}$ for $\mathrm{n}^{-2}$, from Eq. (4-19), gives

$$
Q_{s}=\frac{\omega\left(\varepsilon_{0} z_{1}+\varepsilon_{0} s\right)}{\omega \varepsilon_{0} \varepsilon^{\prime \prime} s / \varepsilon^{\prime}+4 M+P_{s}}=\frac{\omega \varepsilon_{0}\left(z_{1}+s\right)}{\omega \varepsilon_{0} \varepsilon^{\prime \prime} s / \varepsilon^{\prime}+4 M+P_{s}} .
$$

The term $\left(z_{1}+s\right)$ can be set equal to $d$ for $s$ that is small in comparison to the resonator spacing, and by dividing $\mathrm{Eq} .(4-68)$ by $\omega$ and $\varepsilon_{0}$ we obtain

$$
Q_{s}=\frac{d}{\varepsilon^{\prime \prime} s / \varepsilon^{\prime}+\left(4 M+P_{s}\right) / \omega \varepsilon_{0}} \text {. }
$$

\subsection{DERIVATION OF THE EXPRESSION FOR RESISTIVITY}

The loss tangent may also be defined [65] as

$$
\tan \delta=\frac{\varepsilon^{\prime \prime}}{\varepsilon^{\prime}}
$$

Equation $(4-69)$ is rewritten:

$$
Q_{S}=\frac{d}{s \tan \delta+\left(4 M+P_{0}\right) / \omega \varepsilon_{0}} .
$$

By inverting Eq. $(4-71)$, the following relation is obtained:

$$
\frac{1}{Q_{s}}=\frac{s \tan \delta}{d}+\frac{1}{d}\left(\frac{4 M+P s}{\omega \varepsilon_{0}}\right)
$$

or, by Eq. (4-64), we find

$$
\frac{1}{Q_{s}}=\frac{s \tan \delta}{d}+\frac{1}{Q_{0}}
$$


Solving for $\tan \delta$ yields

which may be solved to give

$$
\tan \delta=\frac{\mathrm{d}}{\mathrm{s}}\left(\frac{1}{\mathrm{Q}_{\mathrm{s}}}-\frac{1}{\mathrm{Q}_{0}}\right),
$$

$$
\rho=\frac{s}{2 \pi f \varepsilon_{d}}\left(\frac{1}{Q_{s}}-\frac{1}{Q_{0}}\right)^{-1}
$$

from

$$
\tan \delta=\frac{\sigma}{\omega \varepsilon}=\frac{1}{\rho 2 \pi f \varepsilon}
$$

It is the expression for $\rho$ in Eq. (4-75) that presents the most appealing solution in terms of an easy measurement. Measurements can be made for $Q_{0}$ when the sample is not present and for $Q_{s}$ when the film is mounted. With knowledge of the film thickness and the distance between reflectors, calculation of the film resistivity is a simple procedure. We hoped that experimental measurements would verify the above equation as a viable solution. 


\section{S=Pl:}




\section{SECTION 5.0}

\section{EXPERIMENTAL SETUR}

We assembled the experimental apparatus with the goal of keeping it as simple as possible. From the discussion of the theory, it is evident that all that was needed was a method to measure the $Q$ of the resonator. By use of welldocumented techniques, the measurement was made using only a standing wave probe and frequency meter. The signal source was a reflex klystron. Figure 5-1 shows a block diagram of the experimental apparatus that was assembled.

The klystron was a Varian VC-710, which demonstrated a frequency range from 90 to $94 \mathrm{GHz}$. It was powered by a PRD TYPE $815 \mathrm{klystron}$ power supply. The power supply was typically run at a beam voltage of $2400 \mathrm{~V}$ at $12 \mathrm{~mA}$. The reflector voltage, modulated by a $40-\mathrm{V}$ square wave signal at $1000 \mathrm{~Hz}$, indicated an optimum oscillation when set at about $180 \mathrm{~V}$. The modulation was performed so that the detector meter could be used, and it was optimized by delivering the maximum detector current at matched frequency. The klystron, a 75-mW device, required water cooling, which was accomplished using a small recirculating water pump and a two-quart metal pan for water holding and cooling.

The isolator was a TRG Inc. model 非112-36, which utilized a ferrite material, reduced unwanted modes within the waveguide, and added to the frequency stability of the klystron by eliminating loading effects seen by the generator.

The wavemeter, designed and assembled at the University of Colorado, was a resonator-styled indicator. Unfortunately, no data existed as to its operation, so we spent a substantial amount of time on its calibration and design parameters. This information, due to its length, is summarized in Appendix A. It was possible to determine frequency with the metcr with an accuracy good to the fourth digit.

The standing wave indicator, built by the N.B.S. Boulder Labs., was a unit with a $1-\mathrm{cm}$ range of travel. The probe depth into the fields was adjusted so as to produce a nearly ideal sine square response when the probe traversed over the $1-\mathrm{cm}$ length of travel. Tunable slugs were adjusted to maximize the signal detected by proper attenuation of the $E$ and $H$ components in the detector waveguide. The detector used was a 1 N53 crystal diode detector which produced good square law behavior. The detected current from the diode was monitored with either an oscilloscope or an HP-415B detector meter. The meter was internally locked to detect a $1000-\mathrm{Hz}$ modulation frequency; for this reason the klystron power supply was adjusted for maximum detection.

The resonator was designed by $F$. Barnes and fabricated at the University of Colorado. Figure 5-2 is a detailed drawing of the resonator with pertinent dimensions. The reflectors were machined out of steel and then coated with gold. The gold film provided high conductivity and hence low power loss reflection coefficient. The reflectors were mounted on an optical bench. The front curved reflector had a gross position adjustment that provided movement along the bench. The rear reflector was fixed to the optical bench but was capable of a micrometer-controlled movement of $1 \mathrm{~cm}$. A steel rule was placed between the two reflectors, so that a reflector spacing of 0 to $12 \mathrm{~cm}$ could be 


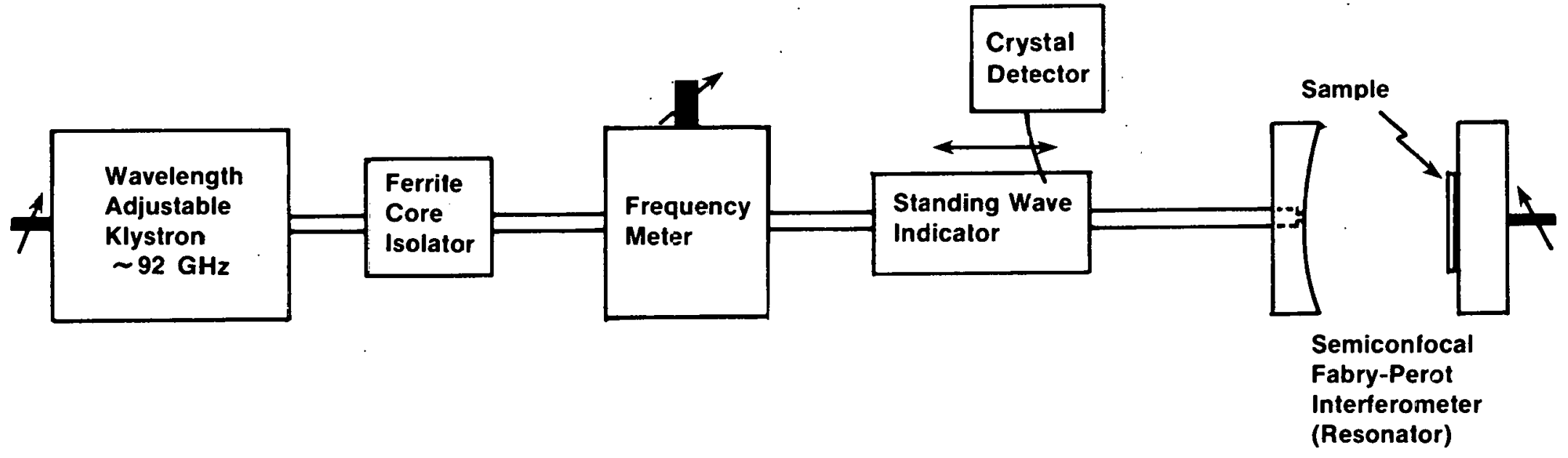

Figure 5-1. Microwave Resistivity Measurement Apparatus 


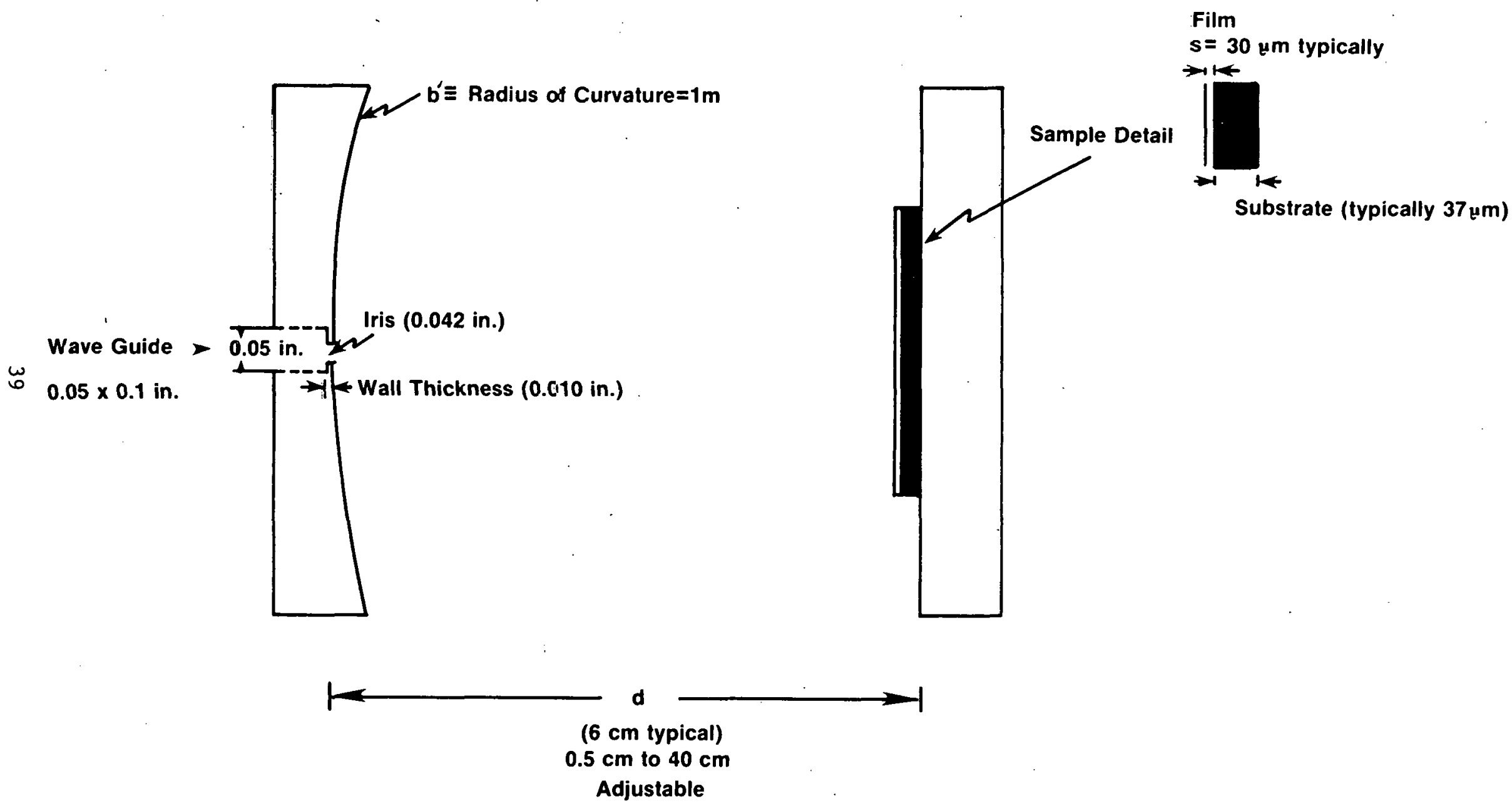

Figure 5-2. Resonator Detai!

茎 
easily determined. This design was very useful for measurements. The measurement. of the reflector movement was not sufficiently accurate, however, to allow techniques used by other researchers, e.g., length retuning. Other dimensions also might have been optimized by a review of the work of Sheppard and Rothamal, which detailed optimization of obtainable $Q$ with regard to parameters such as iris size [62]. The rest of the equipment was also mounted on an optical bench to achieve a height match. Figure 5-3 shows a photograph of the setup. 


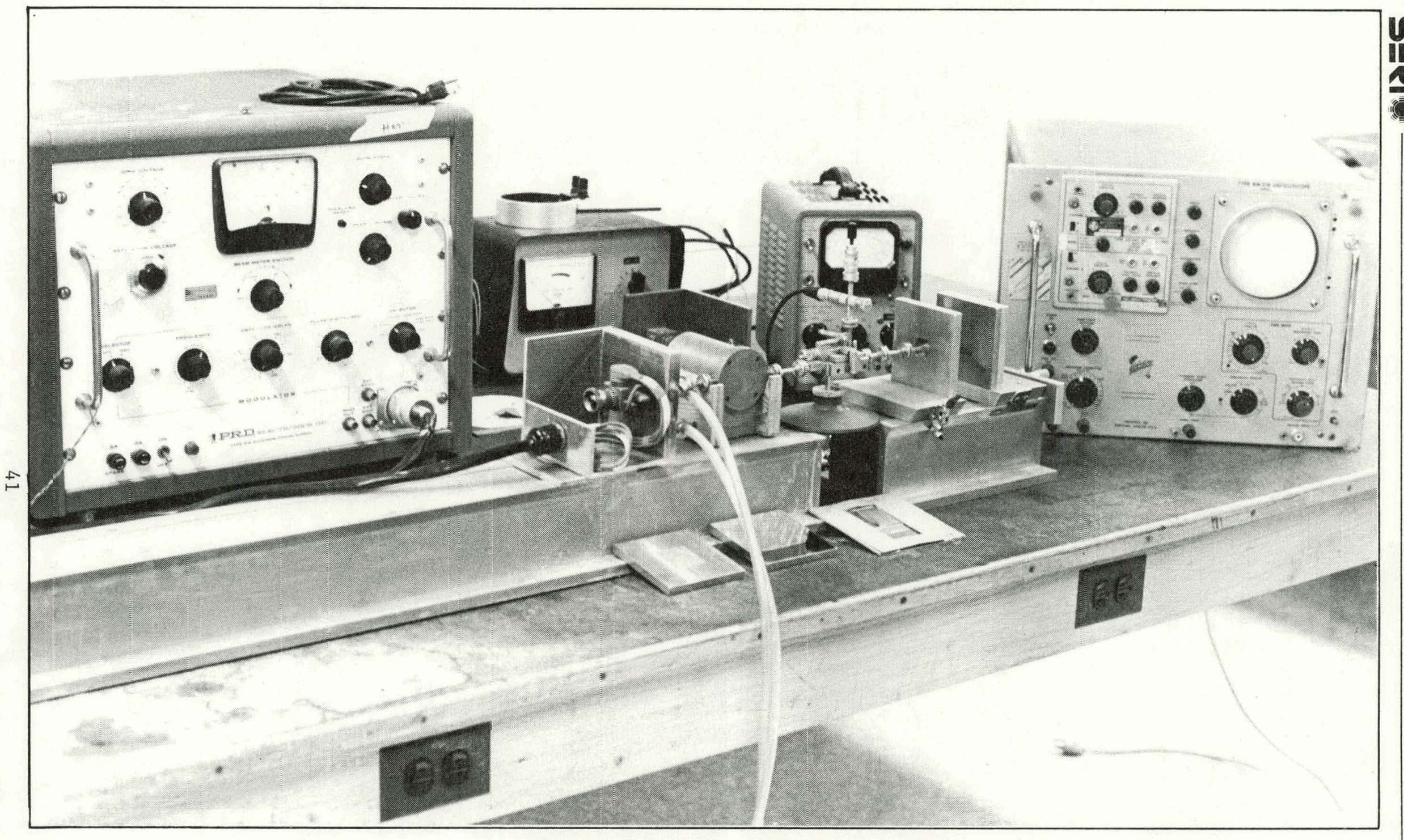

Figure 5-3. Photograph of Experimental Setup 
SERा 


\section{SECTION 6.0}

\section{EXPERIMENTAL RESULTS}

The measurement of interest described in Section 4.0 is the value of resonator Q. The Fabry-Perot resonator was initially set up with both reflectors gold plated so that baseline $Q_{0}$ studies could be made. Initial efforts at detecting Q proved discouraging: no resonance could be detected. After a thorough analysis, in which an $\mathrm{E}-\mathrm{H}$ tuner was used to attempt a maximum coupling, it was discovered that solder had run around the waveguide walls when it was joined to the curved reflector. This effectively changed the wall thickness from 0.010 in., as shown in Fig. 5-2, to almost 0.050 in., so that the field transmission through the iris was blocked. After correction of the problem, a definite resonance was detected as the back reflector was moved.

\subsection{TECHNIQUE FOR MEASUREMENT OF Q}

Measurements of $Q$ were made by the standing wave ratio method of Ginzton [12]. In summary, the method is as follows:

(1) Detune resonator completely.

(2) Using the Standing Wave Indicator (SWI), locate a minimum in the standing wave pattern. This indicates a detuned short position. Note position.

(3) Tune resonator to resonance, as indicated by either an increase in signal level at the detuned short, or a decrease in signal at the SWR maximum.

(4) Explore the SWR to ascertain that the previously located minimum now represents either a maximum or a minimum reading while in resonance.

(5) If the previous minimum is still a minimum, the resonator is undercoupled. If it is now a maximum, the resonator is overcoupled.

(6) With cavity in resonance, measure the VSWR; VSWR value $\equiv \mathrm{r}_{0}$.

(7) Calculate $\beta$, the coupling coefficient, from:

a) $\beta=1 / r_{0}$, if resonator is undercoupled;

b) $\beta=r_{0}$, if resonator is overcoupled.

(8) Using the frequency meter, read $f_{0}$, the frequency of resonance.

(9) Using either a Smith chart technique, or the following analytic expressions, calculate the values of half-power VSWRs related to the respective values of $Q$ for the load and resonator, and a quantity $Q_{0}$, where

$$
\begin{aligned}
& \text { for } Q_{0}, \quad\left(r_{1 / 2}\right)_{0}=\frac{2+\beta^{2}+\sqrt{4+\beta^{4}}}{2 \beta}, \\
& \text { for } Q_{L}, \quad\left(r_{1 / 2}\right)_{L}=\frac{1+\beta+\beta^{2}+(1+\beta) \sqrt{1+\beta^{2}}}{\beta},
\end{aligned}
$$


and

$$
\text { for } Q_{E X T}, \quad\left(r_{1 / 2}\right)_{E}=\frac{1+2 \beta^{2}+\sqrt{1+4 \beta^{4}}}{2 \beta} \text {. }
$$

(10) Knowing these values of VSWR, detune the klystron until the desired VSWR is obtained, preferably detuning on both sides of $f_{0}$ to find the frequencies $f_{1}$ and $f_{2}$ that correspond to the particular $r_{1 / 2}$ under mea surement.

(11) Measure the values of $f_{1}$ and $f_{2}$ using the frequency meter.

(12) Calculate the particular Q under measurement as

$$
Q_{x}=\frac{f_{0}}{f_{1}-f_{2}} .
$$

It should be noted that $Q_{0}$ is the $Q$ of interest, since it represents the resonator itself. The Q's are related such that

and also

$$
\frac{1}{\mathrm{Q}_{\mathrm{L}}}=\frac{1}{\mathrm{Q}_{0}}+\frac{1}{\mathrm{Q}_{\mathrm{EXT}}}
$$

$$
\begin{gathered}
\mathrm{Q}_{\mathrm{EXT}}=\frac{\mathrm{Q}_{0}}{\beta}, \\
\mathrm{Q}_{0}=(1+\beta) \mathrm{Q}_{\mathrm{L}} .
\end{gathered}
$$

The reflection coefficient $\Gamma$ can also be determined from the value of $r_{0}$ from

$$
r_{0} \equiv \frac{1+|\Gamma|}{1-|\Gamma|}
$$

In all cases of measurement, the cavity was found to be overcoupled. For convenience, since $Q$ vs. $f$ is symmetric about $f_{0}[12]$, the klystron was only detuned in one direction. Using this frequency, we calculated $Q$ as

$$
Q=\frac{f_{0}}{2\left(f_{1}-f_{0}\right)} \text {. }
$$

The value chosen for $r_{1 / 2}$ was generally calculated from Eq. (6-3); however, the Smith chart method was used also to verify results. The Smith chart method, shown in Fig. 6-1, consists of drawing the constant $\beta$ or $\mathrm{r}_{0}$ curve on the chart, with a passage through $0+j 0$, then constructing lines of constant characteristics as described by Ginzton. The intersections of these lines with the circle represent the half-power VSWR points to be attained.

We further modified the actual Q measurement technique. Starting with Eq. (5-9) and substituting wavelength for frequency gives

$$
Q=\frac{\lambda_{0} / c}{2\left(\lambda_{0}-\lambda_{1}\right) / c}=\frac{\lambda_{0}}{2\left(\lambda_{0}-\lambda_{1}\right)} .
$$


IMPEDANCE OR ADMITTANCE COORDINATES
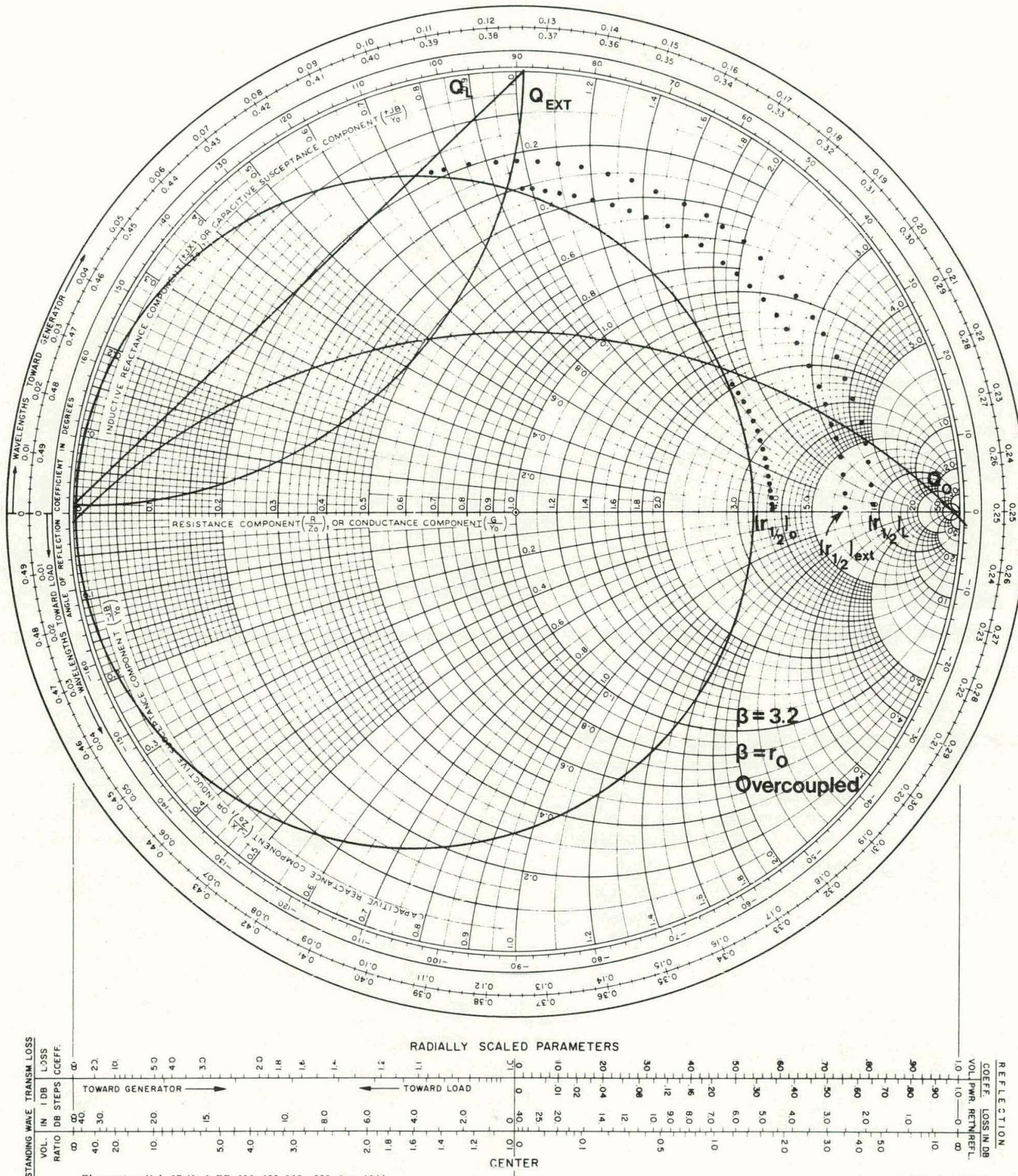

Elecinonics. Vol. 17, No.1, PP. 130-133,318-325, Jan. 1944

Figure 6-1. Smith Chart Calculation of Half-Power Point 
The frequency meter (see Appendix A) had the following micrometer-dial-reading-to-wavelength conversion:

$$
\lambda=\frac{d}{q+(1 / 2 \pi) \cos ^{-1}(1-d / b)},
$$

where

$$
\mathrm{d}=[(1.5+\mathrm{x}) 2] 2.54 \text { in. }
$$

and $\mathrm{x}$ is the micrometer dial reading.

The value of $q$ was ascertained to be 27 . The factor of $(1 / 2 \pi) \cos ^{-1}(1-d / b)$ was typical1y 0.1 to $0.2--$ much 1 ess than $27--$ so it was ignored. Equation (6-12) then becomes

$$
\lambda=\frac{\mathrm{d}}{\mathrm{q}}
$$

This leaves the value of $Q$ as

$$
Q \simeq \frac{d_{0}}{2\left(d_{0}-d_{1}\right)} .
$$

Thus, a convenient measurement of $Q$ was made simply by reading the micrometer dial on the wavemeter.

\subsection{UNLOADED CAVITY Q MEASUREMENTS}

With the gold-plated back reflector mounced, a mullitude of $Q$ measurcments were made. These measurements deviated greatly from the expected Q, as seen in Fig. 6-2. The values represented in Fig. 6-2 were derived from the averages given in Table 6-1.

Table 6-1. Q vs. d

\begin{tabular}{cr}
\hline $\begin{array}{c}\text { distance } \\
(\mathrm{cm})\end{array}$ & $\mathrm{Q}$ \\
\hline 1 & 14,000 \\
2 & 20,000 \\
3 & 12,000 \\
4 & 4,000 \\
5 & 6,600 \\
6 & 8,000 \\
7 & 11,000 \\
8 & 13,000 \\
9 & 8,000 \\
10 & 5,000 \\
11 & 3,000 \\
\hline
\end{tabular}


The explanation for the deviations of the readings from the linear ideal condition is twofold. The problem at the close spacings is expected, as per an explanation by Culshaw; a minimum distance of

$$
2 d \simeq 0.25 \mathrm{a}^{2} / \lambda
$$

is required for proper resonance [9]. Culshaw showed that for spacings closer than that value, multiple modes exist in the resonator. These multiple modes then add to the apparent value of $Q$ in that the resonator is not restricted to the TEM ${ }_{\text {oog }}$ mode. Diffraction effects, observed previously $[9,59]$, explain the anomalous behavior at distances greater than $8 \mathrm{~cm}$.

We decided to limit calculations to the area around $6 \mathrm{~cm}$. This value was chosen due to the excellent reproducibility of measurements made at that distance. Also, it avoided the problem of close spacings in that it was close to the $\mathrm{d}=(0.25 / 2)\left(\mathrm{a}^{2} / \lambda\right)$ requirement. In addition, at that distance the separation between resonance points was the expected value of the TEM ooq for the variation in $q$.

\subsection{LOADED CAEITY Q MEASUREMENTS}

Over a period of three months, three samples of different CdS filn resistivity on brass substrates were received from the Institute of Energy Conversion at the University of Delaware. The films, deposited on a $37-\mu \mathrm{m}$ brass substrate, measured $7.6 \mathrm{~cm}$ by $7.6 \mathrm{~cm}$. As a result of the spot size calculation, the substrates were divided into $3.8-\mathrm{cm}$ square samples. Three gold-plated back plates were available; one was kept as a flat gold surface to serve as a control sample. A piece of $51-\mu_{\mathrm{m}}$ brass shim stock was cut into a $3.8 \mathrm{~cm}$ square and mounted in the center of a second back plate. This served as the plate for measuring $Q_{0}$ in that it was most like the film sample in resonator perturbation and also was the same field-terminating material as was behind the films. The skin depth in the brass was found to be around $0.4 \mathrm{~lm}$ and thus orders of magnitude less than the thickness. The brass samples, as well as. the film on brass samples, were mounted to the back plate with a low-meltingpoint wax. The mounted samples were held to the back plate after the wax reached its melting temperature and recooled, thus ensuring a surface as flat as the film.

The three CdS films ranged in thickness from $30 \mu \mathrm{m}$ to $38 \mu \mathrm{m}$ and had skin depths ranging from $300 \mathrm{~km}$ to $5 \mathrm{~mm}$; therefore, in all cases the skin depth was substantially greater than the sample thickness. The method of measurement for all samples was first to measure the $Q$ of the back plate with the brass, i.e., $Q_{0}$, then install the back plate of CdS-mounted film, maintaining the same $d$. This ensured the same mode of q. Table 6-2 shows typical values of test runs for the three samples, which were numbered $715,740 \mathrm{~A}$, and $763 \mathrm{~A}$. 
Table 6-2. MEASURED Q VALUES

\begin{tabular}{|c|c|c|c|c|c|}
\hline \multicolumn{2}{|c|}{ Sample 715} & \multicolumn{2}{|c|}{ Sample $740 \mathrm{~A}$} & \multicolumn{2}{|c|}{ Sample 763A } \\
\hline Brass $Q_{0}$ & Sample $Q_{S}$ & Brass $Q_{0}$ & Sample $Q_{\mathbf{S}}$ & Brass $Q_{0}$ & Sample $Q_{s}$ \\
\hline 6774 & 2752 & 1332 & 439 & 4383 & 3985 \\
\hline 6290 & 2936 & 1542 & 408 & 3984 & 3985 \\
\hline 5504 & 2446 & -- & - & 4175 & 3371 \\
\hline 8807 & 2320 & - & - & 4174 & 3371 \\
\hline 6775 & -- & - & - & -- & - \\
\hline 7339 & - & - & - & -- & -- \\
\hline \multicolumn{6}{|c|}{ Average Values } \\
\hline 6915 & 2613 & 1437 & 423 & 4179 & 3678 \\
\hline
\end{tabular}

The data given in Table 6-2 should not be construed to indicate a one-to-one correlation on each line. Each column represents measurements made at one time; the variations are due to experimental technique and are discussed in Section 7.0. We also suspect that the differences in the $Q_{0}$ values are due to back plate tilts.

\subsection{MEASURED SARPLE RESISTIVITY}

The value of $\rho$ was calculated as per Eq. (4-75):

$$
\rho=\frac{\mathrm{s}}{2 \pi \mathrm{f} \varepsilon \mathrm{d}}\left(\frac{1}{\mathrm{Q}_{\mathrm{s}}}-\frac{1}{\mathrm{Q}_{0}}\right)^{-1} \text {. }
$$

The values of the parameters are given in Table 6-3.

Table 6-3. FILM SAMPLE PARAMETERS

\begin{tabular}{llll}
\hline & \multicolumn{3}{c}{ Sample } \\
\cline { 2 - 4 } Parameter & \multicolumn{1}{c}{715} & \multicolumn{1}{c}{$740 \mathrm{~A}$} & $763 \mathrm{~A}$ \\
\hline $\mathrm{s}(\mu \mathrm{m})^{\mathrm{a}}$ & 30 & 38.4 & 30.1 \\
$\mathrm{f}(\mathrm{Hz})^{\mathrm{b}}$ & $91.16 \times 10^{9}$ & $91.32 \times 10^{9}$ & $91.57 \times 10^{9}$ \\
$\varepsilon(\mathrm{F} / \mathrm{cm})$ & $8.59 \times 10^{-13}$ & $8.59 \times 10^{-13}$ & $8.59 \times 10^{-13}$ \\
$\mathrm{~d}(\mathrm{~cm})$ & 6.0 & 6.23 & 6.34 \\
$\mathrm{Q}_{\mathrm{s}}$ & 2613 & 423 & 3678 \\
$\mathrm{Q}_{0}$ & 6915 & 1437 & 4179 \\
\hline
\end{tabular}

${ }^{a}$ As measured by the University of Delaware
$\mathrm{b}_{\text {As determined from the wavemeter }}$ 
The values in Table 6-3 yield the resistivities listed in Table 6-4.

Table 6-4. SAMPLE RESISTIVITY

\begin{tabular}{cc}
\hline Sample & $\begin{array}{c}\text { Resistivity } \\
(\Omega \mathrm{cm})\end{array}$ \\
\hline 715 & 4.3 \\
$740 \mathrm{~A}$ & 0.7 \\
$763 \mathrm{~A}$ & 29.5 \\
\hline
\end{tabular}

These resistivity values are compared with the values obtained by another technique in Section 8.0 . 


\section{SECTION 7.0}

\section{ERROR ANALYSIS AND LIMITATIONS}

The successful use of this technique for resistivity measurements requires an awareness of limitations in two areas, theoretical and physical. Theoretical considerations involve film thickness, phase shifts, sample size and mounting, and cavity design. Physical limitations include the accuracy of the frequency reading method, sample size, klystron frequency stability, and system noise.

\section{7-1 THEORETICAL CONSIDERATIONS}

Close analysis of the theory shows that the single most important limitation involves film thickness. The first limitation encountered is the assumption that the $\mathrm{E}$ field is zero at the substrate interface. A more detailed analysis can be developed that sets up a field in the substrate. The substrate thickness may be considered infinite if it is much greater than the skin depth into the substrate, so that no returning traveling plane wave is present. As in our analysis, tangential components are assumed continuous across the filmsubstrate interface and a solution can be found. The approximation of the field as zero is justifiable on one condition, however: the film thickness must be much greater than the skin depth. The substrate also must be substantially thicker than its skin depth, but there is no connection between film and substrate thickness. Recalling the test conditions, we find from Eq. (3-21) that the skin depth into the brass substrate is $0.3 \mu \mathrm{m}$. This is two orders of magnitude less than the typical film thickness of about $30 \mu \mathrm{m}$. In discussions of the theory with E. F. Kuester, it was agreed that errors introduced from this approximation would directly correlate with the magnitudes involved. Thus, a 30- $\mu_{m}$ sample thickness on a substrate with a skin depth of $0.3 \mathrm{~km}$ would yield an error of $1 \%$. This error, as discussed in detail later in this section, is certainly less than the limitations imposed by the physical setup.

A second limitation imposed by the theory proves more restrictive in practical cases. A film thickness much less than the skin depth was assumed so that the E field could be assumed to be the same on both sides of the film. Although this satisfies amplitude considerations, it does not consider phase shift within the material. Therefore, it is necessary to compare the film thickness to the wavelength within the sample. The film.thickness must be much less than the wavelength in order to prevent a marked phase shift. Should the thickness of the sample be comparable in magnitude to the wavelength within the film, a further complication occurs in the possibility of internal resonance within the sample. Either situation, internal resonance or substantial phase shift, will completely invalidate the plane wave theory developed in this report. Considering again the measurements reported in Section 6.0, we can verify the acceptable approximations. The wavelength in the material can be determined from the following equation:

$$
\lambda_{\mathrm{CdS}}=\frac{\lambda_{\text {source }}}{\mathrm{n}}=\frac{\lambda_{\text {source }}}{\sqrt{\varepsilon_{\mathbf{r}}}}
$$


This yields a wavelength of

$$
\lambda_{\mathrm{CdS}}=\frac{3.55 \mathrm{~mm}}{\sqrt{9.7}}=1.04 \mathrm{~mm},
$$

which again is much greater than the film thickness of $30 \mu_{m}$. It does, however, provide an upper limit to the film thickness. A modification of source frequency would help should such a problem occur, but the other considerations mentioned previously would have to be reexamined.

A further consideration in phase shift is the effect of the $\omega \tau$ factor involved in the transit of the field through the material. It is a function of the material parameters and the exc1tation frequency. For the CdS samples we can solve for an approximate ' $i$ from

$$
\tau=\frac{\mu_{m}^{*}}{q}
$$

where, for CdS, $\mu=1500 \mathrm{~cm}^{2} / \mathrm{V}$ s and $\mathrm{m}^{*}=(0.2)\left(9.108 \times 10^{-31}\right)$, ylelding

$$
\tau_{\mathrm{CdS}}=2.89 \times 10^{-14} \text {. }
$$

The frequency $\omega$ at $92 \mathrm{GHz}$ is $5.78 \times 10^{11}$, which gives an $\omega \tau$ Cds factor of 0.016. This is a negligible factor when added to the time factor of the field.

A test conducted on a silicon sample whose thickness violated one of the above thickness requirements did yield fallacious results. The sample, a p-type Si wafer, was mounted after an aluminum back coating was deposited. It yielded measurements of a resistivity of $4 \Omega \mathrm{cm}$ by the microwave technique. Prior to Al deposition, a resistivity of $1.88 \Omega \mathrm{cm}$, which agreed with the manufacturer's specifications, was measured by means of the four-point probe technique. The Si sample, however, was $12 \mathrm{mils}$ thick, or $0.32 \mathrm{~mm}$. The calculated wavelength $\lambda_{S i}$ within the sample is $0.95 \mathrm{~mm}$. Thus, a phase shift of around 120 degrees is indicated, obviously enough to invalidate the assumption of no phase shift through the material. Further complications arise when the $\omega t$ si factor is calculated and $\tau_{\mathrm{S} i}$ is found to be $1.7 \times 10^{-13}$, yielding $\omega \tau_{\mathrm{Si}}=0.16$.

With all of the above limitations in mind, it is then possible to determine limits of validity for CdS samples on brass substrates when measured at 92 $\mathrm{GHz}$. Maintenance of $<10 \%$ error requires a minimum film thickness of $3 \mu \mathrm{m}$. To maintain a phase change less than 30 degrees, a maximum thickness of $60 \mu_{m}$ is required. As seen, the films analyzed were conveniently well within these bounds. Most present manufacturing techniques produce thin films that satisfy these requirements. However, the thickness restrictions might limit severely a potential use of the system: application of the technique to thin films grown epitaxially on substrates. Since the substrates often are not highly conductive, close attention must be given to the different thickness limitations, particularly the skin depth into the substrate. For higher resistivity material the skin depth becomes quite deep, such that the film thickness becomes much less than the skin depth. In such cases, the necessary approach to the problem is to use prolate spheroidal coordinates and solve the problem ex- 
actly. This destroys much of the usefulness of the technique unless sophisticated computing power is built into the test system.

As discussed previously in this report, the theoretical analysis assuming plane waves also restricts sample size. The dimensions of the film must be greater than the spot size, such that an approximation of the field intensity slowly decaying to an infinite distance from the center axis is acceptable. This should present no problems in testing because $4-\mathrm{cm}$ square samples are adequate and samples of much larger dimensions are easily fabricated. Another consideration is that in the system we are describing, the film must be intimately backed by a highly conducting substrate. Mounting a sample, such as Si, directly onto the back plate causes the problem of interaction of the field with the mounting wax. It is therefore necessary to terminate the field before the wax mount surface.

The final theoretical limitation to be considered involves the cavity and resonator theory. The resonator fabricated and used in this work was limited to consistent $Q$ measurements of 7000. Modifications suggested by Sheppard and Rothamel [62] on semi-confocal resonator construction could improve this $Q$.

A smaller radius of curvature would guarantee operation in the TEM oog mode over a broader range of reflector separation. This would give a wider flexibility in sample size and lower diffractive losses. A reduction in iris size would also improve the $Q$, as would the use of copper-plated, instead of goldplated, reflectors. Taking all modifications into account, it should not be unreasonable to attain consistently a $Q$ of 20,000 . The improvement in capability by such a modification can be seen by a calculation of the maximum resistivity that can be measured at the two different values of $Q$. Using typical values from our experiment, we calculated

$$
Q=\frac{d_{0}}{2\left(d_{0}-d_{1}\right)},
$$

where $d_{0}$ was around $8.95 \mathrm{~cm}$. The term $\left(d_{0}-d_{1}\right)$ is representative of the resolution obtained, and, as discussed later in this section, came to a best resolution of about $1.0 \mu \mathrm{m}$. Taking a $Q_{0}$ of 7000 we find

$$
7000=\frac{8.95 \mathrm{~cm}}{2\left(\mathrm{~d}_{0}-\mathrm{d}_{1}\right)} \text { or }\left(\mathrm{d}_{0}-\mathrm{d}_{1}\right)=6.4 \times 10^{-4} \mathrm{~cm} \text {. }
$$

The next most accurate measurement js made at $\left(\mathrm{d}_{0}-\mathrm{d}_{1}\right)=6.4 \times 10^{-4} \mathrm{~cm}+1 \times$ $10^{-1 / 4}$, giving a $Q_{S}=8.95 / 2\left(7.4 \times 10^{-4}\right)=6047$.

When this value of $Q$ is inserted into the resistivity equation, Eq. (4-75), we find the maximum measurable resistivity for CdS to be

$$
\rho_{\mathrm{CdS}}=45.1 \Omega \mathrm{cm} .
$$

Now, if the maximum $Q_{0}$ attainable is 20,000 , we find

$$
20,000=8.95 / 2\left(d_{0}-d_{1}\right) ;\left(d_{0}-d_{1}\right)=2.23 \times 10^{-4} .
$$


The best $Q_{S}$ attainable is then

$$
Q_{S}=8.95 / 2\left(2.23 \times 10^{-4}+1 \times 10^{-4}\right)=13,854,
$$

giving a maximum resistivity of

$$
\rho_{\mathrm{CdS}_{\text {MAX }}}=46 \Omega \mathrm{cm} .
$$

Although the improvement is not dramatic, the results demonstrate that the limiting factor in the maximum resistivity is the resolution attainable in the frequency measurement. To obtain higher resistivity measurements, a resolution hetter than $1 \mathrm{Hm}$ is necessary. A subtle advantage of higher $Q$, however, is the ability to determine more accurately the resonance of a sample when it is loaded.

\subsection{PHYSICAL LIMITATIONS}

The physical aspects of the experiment impose further limitations and possible errors. As discussed above, the resolution of frequency measurements plays a major role in the limits of measurable resistivity. In our experiment a wavemeter was used for the frequency measurement. The wavemeter is discussed in Section 5.0 of this report regarding determination of $Q$ directly from the of $f-$ set values read, and it is discussed in detail in Appendix A. The limit of resolution is determined by the accuracy of the reading of the micrometer dial corresponding to reflector spacing travel. The micrometer dial is calibrated in 0.1 mils with extrapolation possible to a figure of five decimal places. For the purpose of our calculations, a series of measurements were taken and then averaged in an attempt to limit the random error involved in visual extrapolations. The fifth digle was wlthin $\pm 10 \%$ uf the average value of the readings. An error analysis in which the different values recorded by the last digit were varied indicated that an error of about $10 \%$ is possible due to the extrapolation process; therefore, all values represent a tolerance of $\pm 5 \%$. This is an important limitation and Appendix $B$ describes a method for overcoming this problem.

A second physical limitation results from background noise. Noise in the system prevented measurements of a $Q$ less than 300. This is the limiting factor for the minimum value of resistivity; that is, using $a Q_{0}$ of 7000 and a $Q_{S}$ of 300 , we can calculate ${ }^{{ }_{C}} \mathrm{CdS}_{\mathrm{MIN}}=0.3 \Omega \mathrm{cm}$. The noise in the system probably has several sources. The klystron itself provides some background radiation, as does the power supply and associated electronic instrumentation. With the open resonator, introduction of ambient radiation is also a possibility. Sophisticated techniques exist, such as those described by Cullen and Davis [69], that minimize the background noise so that lower $Q$ values can be measured. The klystron tuning range then becomes a limiting factor. If $Q$ is too low, the klystron is unable to supply the frequency range required to perform the measurement. The klystron frequency stability also becomes a factor in the measurement technique. The important limitation is that the frequency not shift between the time a VSWR is established and the frequency reading is made. Such errors are minimized by making several readings. 
The physical size of the open resonator limits the maximum size of the sample. With the resonator we used, a film size greater than 4 in. to a side is unuseable. In most practical cases this presents no problems. It is possible to improve measurement accuracy by taking advantage of the resonator characteristics described in section 3.0. This could be done by making a series of measurements along the linear portion of the curve of $Q$ versus reflector spacing. This would allow verification both from examination of $Q$ at a particular distance and from the expected change in $Q$ as the distance changes. Also, the measurements would be used at different nodes to verify that the field distribution was indeed the TEM ${ }_{0 o q}$ distribution. If this was verified, it would also be possible to use the resonator instead of the wavemeter to make the frequency measurements. However, due to the low $Q$ possible with an inserted sample, the wavemeter is more accurate over a broader range of samples.

This section shows that the samples we tested were consistent with the limitations imposed both theoretically and physically. Due to resolutions of the wavemeter used, the accuracy of the readings were within $\pm 5 \%$ of the expected values. Section 8.0 summarizes our technique and results and compares the results with another method. 
SEPI 


\section{SECTION 8.0}

\section{SUMMARY}

We have demonstrated a technique that measures thin-film semiconductor film resistivity on metal substrates. The technique utilizes a Fabry-Perot resonator at millimeter wavelengths, as discussed in Section 3.0. The theoretical analysis involves examination of the field distribution within the resonator and mounted film sample. Two field distribution theories are presented. The more tractable theory rejies on a plane wave assumption of the fields within the resonator and, with this theory, the power loss within the sample is ascertained from an easily measured cavity $Q$ factor. The loss tangent is associated with the power loss, yielding a simple expression for the film resistivity in terms of film parameters, resonator parameters, and the difference in resonator $Q$ with and without a sample loaded. We used this technique, as expressed in Eq. (4-75) of Section 4.0, to determine the resistivity of three samples of CdS film on brass substrate. Section 5.0 discusses the experimental apparatus, while Section 6.0 presents the results for the three samples of varying resistivity. The samples, supplied by. the Institute of Energy Conversion (IEC) at Delaware, were also measured at IEC using a completely different technique: A piece of indium was pressed to the top film surface of a small piece of sample; then the through-film-resistivity of the three samples was determined from current-voltage measurements. Table 8-1 presents the results of both methods. (As explained in Section 7.0, the reliability of measurement using the microwave technique is approximately $10 \%$ )

Table 8-1. FILM RESISTIVITY USING THO METHODS

\begin{tabular}{lcc}
\hline & \multicolumn{3}{c}{ Technique } \\
\cline { 2 - 3 } Sample & $\begin{array}{c}\text { Microwave } \\
(\Omega \mathrm{cm})( \pm 5 \%)\end{array}$ & $\begin{array}{c}\text { IEC } \\
\mathrm{cm})\end{array}$ \\
\hline $740 \Lambda$ & 0.7 & 0.7 \\
715 & 4.3 & 4.2 \\
$763 \mathrm{~A}$ & 29.5 & 30.4 \\
\hline
\end{tabular}

The results from both techniques are quite close and thus very encouraging, as they verify the acceptability of our approximations. The general theory is presented in Section 4.0 so that numerical integrations can be used for samples that do not meet the restrictions outlined in section 7.0 . Thus, the resonator technique remains applicable to a broad range of uses.

Future work on the resonator technique can go in many directions. A redesign of the resonator, as outlined in Section 7.0 should be undertaken. The effects on the sample of both light intensity and temperature can be easily examined because the resonator is open. Such an examination would allow further characterization of the photoconductive properties of the films examined, 
as we11 as the temperature-dependent characteristics. A pulsed technique probably can be developed to allow measurements of carrier lifetimes. The apparatus also might be used to perform automatic measurements; this possibility is discussed in Appendix B, where the potential improvements in resolution, and hence accuracy, by automation are presented.

The results of our work are quite consistent with the results of the different method of measurements used by IEC. The method of measurement is applicable to a thin semiconducting film on a highly conductive substrate. The method is nondestructive to the sample and does not exhibit the problems associated with present resistivity measurement techniques. We consider this to be a significant advance in the field of solar cell material characterization. 
SECTION 9.0

REFERENCES

1. Rothwarf, A.; Barnett, A. IEEE Transactions on Electron Devices. 1977; ED-24; p. 381 .

2. Bell, R.; et al. Proceedings of the 11th IEEE Photovoltaic Specialists Conference. May 1975; p. 497.

3. Fahrenbruch, A.; et al. Proceedings of the 11th IEEE Photovoltaic Specialists Conference. May $1 \overline{975 ; ~ p . ~} 490$.

4. Nakayama, N.; et al. Japanese Journal of Applied Physics. Vol. 15: p. $2281 ; 1976$.

5. Matsumoto, H.; et al. Japanese Journal of Applied Physics. Vol. 16: p. $1283 ; 1977$.

6. Lehovec, K.; Fedotowsky, A. Solar Energy. Vol. 21: p. 81; 1978 .

7. Wolf, M.; Rauschenbach, H. Advanced Energy Conversion. Vo1. 3: p. 455; 1963.

8. Culshaw, W.; Anderson, M. V. National Bureau of Standards Report 6786 . July 1961 .

9. Culshaw, W. Advances in Electronics and Electron Physics. Vol. 15: p. $197 ; 1961$.

10. Bhar, J. N. Proceedings of the IEEE. Vol. 51: p. 1623; 1963.

11. Tremblay, R.; Botvin, A. Applied Optics. Vol. 5: p. 249; 1966.

12. Ginzton, E. L. Microwave Measurements. New York, NY: McGraw-Hill; 1957.

13. Montgomery, C. G. Techniques of Microwave Measurements. New York, NY: McGraw-Hill; 1947 .

14. Kellejian, R.; Jones, C. Microwave Measurements Handbook. New York, NY: McGraw-HiL1; 1965.

15. Lance, A. Introduction to Microwave Theory and Measurements. New York, NY: McGraw-llili; 1964.

16. Kosow, I. L. Microwave Theory and Measurement. Englewood Cliffs, NJ: Prentice-Hall; 1963.

17. Sucher, Fox. Ilandbook of Microwave Measurements. Vol. II. New York, NY: Polytechnical Press; 1963. 
18. Jacobs, H.; et al. Proceedings of the IRE. Vol. 49: p. 928; 1961.

19. Sandus, 0. Proceedings of the IRE. Vol. 50: p. 473; 1962 .

20. Champlin, K. S.; Armstrong, D. B. Proceedings of the IRE. Vo1. 50: p. $232 ; 1962$.

21. Havemann, R. H.; Davis, L. E. IEEE Transactions on Microwave Theory and Techniques. Vo1. MTT-19: p. 113; 1971.

22. Ramey, R. L.; Lewis, T. S. Journal of Applied Physics. Vol. 39: p. $1747 ; 1968$.

23. Chaurasia, H. K.; Voss, W. A. G. IEEE Transactions on Microwave Theory and Techniques. Vol. MTT-21: p. $51 ; 1973$.

24. Lindmayer, J.; Kutsko, M. Solid State Electronics. Vol. 6: p. 377; 1963.

25. Naber, J. A.; Snowden, D. P. Review of Scientific Instruments. Vol. 40: p. $1137 ; 1969$.

26. Champlin, K:; Glover, G.; Holm, J. IEEE Transactions on Instrumentation and Measurements. Vol. IM-18: p. 105; 1969.

27. Nag, B. R.; Roy, S. K. Proceedings of the IRE. Vol. 50: p. 2515; 1962.

28. Nag, B. R.; Roy, S. K.; Chatterji, C. K. Proceedings of the IRE. Vol. 51: p. $962 ; 1963$.

29. Nag, B. R.; Roy, S. K.; Chatterji, C. K. Proceedings of the IRE. Vol. 52: p. $185 ; 1964$.

30. Gunn, M. W. Proceedings of the IRE. Vol. 52: p. 185; 1964 .

31. Holmes, D.; Feucht, D.; Jacobs, H. Solid State Electronics. Vo1. 7: p. $267 ; 1964$.

32. McKinney, C. M.; Duff, B. M. Review of Scient1f1c Instruments. Vol. 25: p. $925 ; 1954$.

33. Allerton, G. L.; Seiffert, J. R. IRE Transactions on Instrumentation. Vol. IM-9: p. $175 ; 1960$.

34. Champlin, K. S.; Krongard, R. R. IRE Transactions on Microwave Theory and Techniques. Vol. MTT-9: p. 545; 1961 .

35. Linhart, J. G.; et al. British Journal of App1ied Physics. Vol. 7: p. $36 ; 1956$.

36. Kohane, T.; Sirvetz, M. H. Review of Scientific Instruments. Vo1. 30: p. $1059 ; 1959$. 
37. Owston, C. N. Non-Destructive Testing. Vol. 2: p. 193; 1969.

38. Kohane, T. IRE Transactions on Instrumentation. Vol. IM-9: p. 184; 1960.

39. Bichara, M. R. E.; Poitevin, J. P. R. IEEE Transactions on Instrumentation Measurement. Vol. IM-13: p. 323; 1964 .

40. Orgeret, M.; Boucher, J. Rev. Phys. Appl. (France). Vol. 13: p. 29; 1978.

41. Danilov, G. N.; et al. Pribory I Tekhnika Eksperimenta. Vol. 3: p. 923; 1973.

42. Akhmanaev, V. B.; et a1. Pribory I Tekhnika Eksperimenta. Vol. 3: p. $1650 ; 1973$.

43. Roussy, G.; Felden, M. IEEE Transactions on Microwave Theory and Techniques. Vo1 MTT-14: p. 171; 1966.

44. Covington, D. W.; Ray, D. C. Solid State Electronics. Vol. 16: p. 301; 1973.

45. Portis, A. M. Journal of Physical and Chemical Solids. Vol. 8: p. 326; 1959.

46. Pethig, R.; South, R. B. IEEE Transactions on Instrumentation and Measurements. Vol. IM-23: p. 460; 1974.

47. Eley, D. D.; Pethig, R. Discussions of the Faraday Society. Vol. 51: p. $164 ; 1971$.

48. Watanabe, Y.; et al. Japanese Journal of Applied Physics. Vol. 16: p. 2007; 1977.

49. Cullen, A. L.; Yu, P. K. Proceedings of the Royal Society of London A. Vol. 325: p. 493; 1971.

50. Degenford, J. E.; Coleman, P. D. Proceedings of the IEEE. Vol. 54 : p. 520; 1966 .

51. Degenford, J. E. IEEE Transactions on Instrumentation and Measurement. Vol. IM-17: p. $413 ; 1968$.

52. Breeden, K. H.; Sheppard, A. P. Microwave Journal. Vol. 10: p. 59; 1967.

53. Breeden, K. H.; Langley, J. B. Review of Scientific Instruments. Vol. 40: p. 1162; 1969.

54. Cook, R. J.; Jones, R.; Rosenberg, C. IEEE Transactions on Instrumentation and Measurement. Vol. IM-23: p. 438; 1974 . 
55. Anderson, M. V. PhD thesis. University of Colorado; 1971.

56. Culshaw, W. IRE Transactions on Microwave Theory and Techniques. Vol. MTT-7: p. $221 ; 1959$.

57. Culshaw, W. IRE Transactions on Microwave Theory and Techniques. Vol. MTT-8: p. $182 ; 1960$.

58. Culshaw, W. IRE Transactions on Microwave Theory and Techniques. Vol. MTT-9: p. $135 ; 1961$.

59. Temple, R. E. PhD thesis. University of Colorado; 1971.

60. Fox, A. G.; Li, T. Bell System Technical Journal. Vol. 40: p. 453; 1961 .

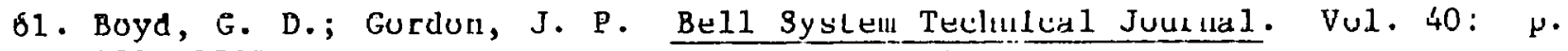
489; 1961 .

62. Sheppard A. P.; Rothame1, W. J. Microwave Journal. Vo1. 10: p. 73; 1967.

63. Boyd, G. D.; Kogelnik, H. Bell System Technical Journal. Vol. 41: p. $1347 ; 1962$.

64. CRC Handbook of Chemistry and Physics. Cleveland, OH: CRC Press; 1972.

65. Johnk, C. T. A. Engineering Electromagnetic Fields and Waves. New York, NY: John Wiley and Sons; 1975.

66. Culshaw, W. IRE Transactions on Microwave Theory and Techniques. Vol. IIIT $=10:$ p. $331 ; 1962$.

67. Lotsch, H. K. V. Proceedings of the IEEE. Vol. 53: p. 489; 1965 .

68. Kogelnik, H.; Li, T. Proceedings of the IEEE. Vol. 54: p. 1312; 1966.

69. Cullen, A.; Davies, A. Microwave, Optics and Acoustics. Vol. 2: p. 77; 1978. 


\section{APPENDIX A}

\section{WAVEMETER}

The wavemeter was uncalibrated, so it was necessary to study its design in detail. By disassembling the cavity, we measured the dimensions shown in Fig. A-1. The cavity was a semiconfocal resonator. The condition of resonance, as shown by Boyd and Kogelnik, is given by

$$
\frac{2 d}{\lambda}=q+\frac{1}{2 \pi}(m+n+1) \cos ^{-1}\left(1-\frac{2 d}{b}\right),
$$

where $q$. is the longitudinal mode number and $m$ and $n$ are the transverse mode numbers [63]. At first we assumed that the cavity was designed to operate in the $\mathrm{TEM}_{110}$ mode. Calculations indicated that the range of frequency measurement for this mode for $\mathrm{d}$ of $1.5 \mathrm{in}$. to $2.5 \mathrm{in}$. would be $118 \mathrm{GHz}$ to $95 \mathrm{GHz}$.

It was then ascertained, as should have been obvious from the lossy material lining the inside of the cavity and the lack of electrical contact between the side walls and the back reflector, that the cavity was designed for use in the TEM ${ }_{\text {ooq }}$ mode. This yields the familiar equation for the many degenerate modes q:

$$
\lambda=\frac{2 d}{q+(1 / 2 \pi) \cos ^{-1}(1-2 d / b)} \text {. }
$$

In Eq. A-2 the value of $q$ for each particular $d$ is unknown. The value of $q$ can be determined by measuring $d$ at one wavelength of resonance and then determining the next value of $d$ at the same wavelength, i.e., at $q+1$. This method is represented in the following equation:

$$
\frac{2 d_{1}}{q+(1 / 2 \pi) \cos ^{-1}\left(1-2 d_{1} / b\right)}=\frac{2 d_{2}}{(q+1)+(1 / 2 \pi) \cos ^{-1}\left(1-2 d_{2} / b\right)} \cdot(A-3)
$$

The following measurements were made with the klystron set at a single frequency:

\begin{tabular}{cc}
$\begin{array}{c}\text { Micrometer Setting for:Resonance (X) } \\
\text { (in.) }\end{array}$ & VSWR \\
\hline 0.1307 & 1.15 \\
0.1648 & 1.05 \\
0.1944 & 1.13 \\
0.2277 & 1.06 \\
0.2583 & 1.15 \\
0.2908 & 1.05
\end{tabular}

Two of the micrometer settings that gave greater values of VSWR were considered as representative of resonance at $\lambda$, and the weaker VSWR values were considered as representative of resonance at $\lambda / 2$. Thus, the two stronger values, 0.1944 and 0.2583 , or 


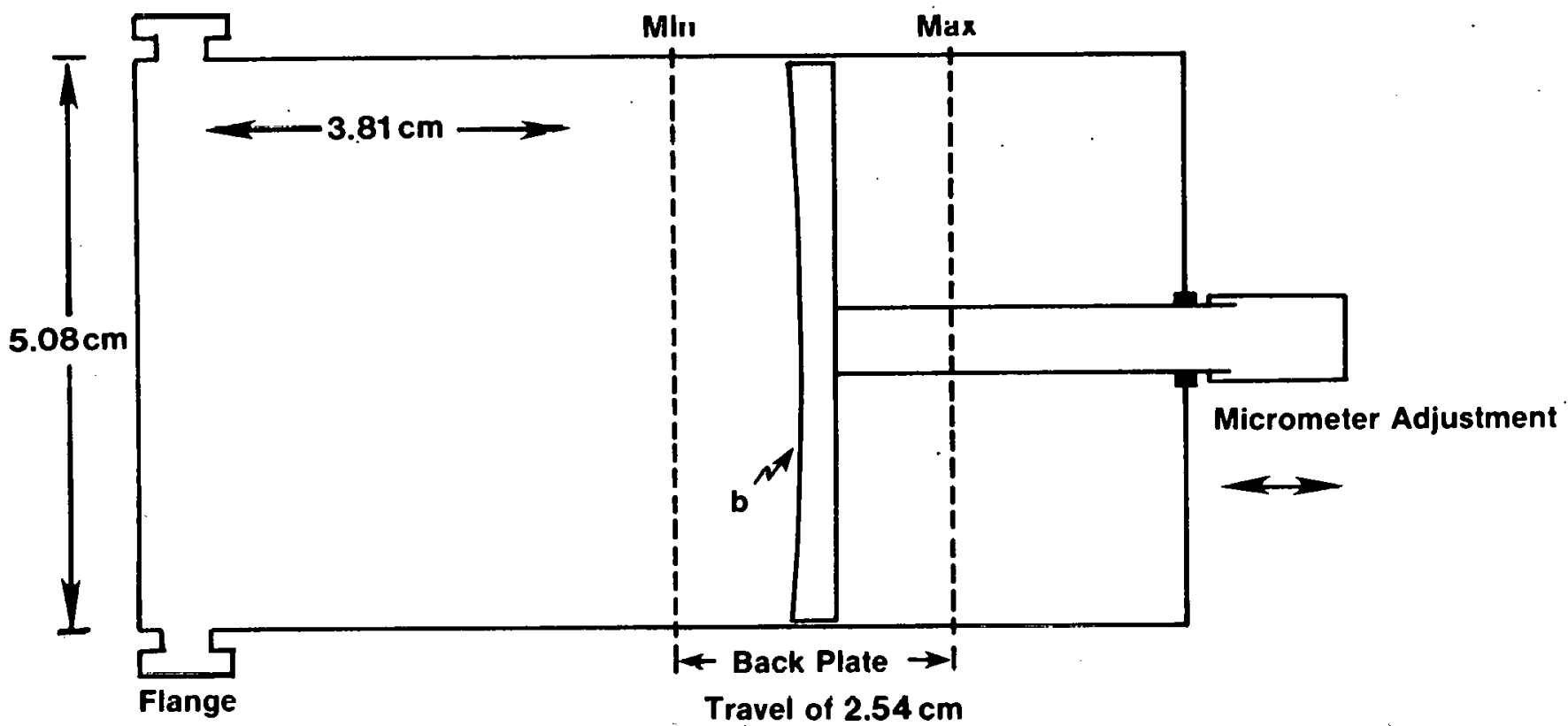

Figure A-1. Wavemeter 


$$
\mathrm{d}_{1}=(1.5+0.1944) \text { in. }=8.6076 \mathrm{~cm}
$$

and

$$
\mathrm{d}_{2}=(1.5+0.2583) \text { in. }=8.9322 \mathrm{~cm} \text {, }
$$

were chosen to calculate $q$. Inserting these values into Eq. (A-3), we obtain

$$
\frac{8.6076}{q+0.18 \overline{7} \overline{3}}=\frac{8.9322}{q+1.1912 \overline{8}} \text {, }
$$

which can be solved for

$$
q=26 \text { at } x=0.1944
$$

and

$$
q=27 \text { at } x=0.2583 \text {. }
$$

When these values for $q$ are reinserted into Eq. $(A-2)$, we obtain

$$
\text { for } \mathrm{q}=26, \lambda=\frac{8.6076}{26+0.1873}=3.28 \mathrm{~mm}
$$

and

$$
\text { for } \mathrm{q}=27, \lambda=\frac{8.9322}{27+0.19128}=3.28 \mathrm{~mm} \text {, }
$$

or

$$
\mathrm{f}=91.27 \mathrm{GHz} .
$$

We attempted to verify the above results by using the standing wave indicator. This was done by inserting a short instead of the cavity at the end of the setup. The distance between the null detector readings was measured and this value was used to calculate the free-space wavelength. Since the null readings were at background level, values at given power levels on both sides of the null were read and the null value was taken as half the value of the difference. This can be done because the SWI detector is a square law crystal; that is, it presents a sine-square representation as the probe is slid through the standing wave pattern. A peak and nuli are detected every half-wavelength of the signal in the waveguide and they can then be correlated to the freespace wavelength. Measurements taken with the attached short revealed a halfwavelength of $1.77 \mathrm{~mm}$. As Ginzton describes (p. 348 of Ref. 12), the value obtained for the wavelength is related to the free-space wavelength $\lambda_{0}$ by

$$
\lambda_{0}=\frac{2 L}{\sqrt{1+\left(2 L / \lambda_{c}\right)^{2}}},
$$


where $L$ represents the measured half-wavelength $(1.77 \mathrm{~mm})$ and $\lambda_{c}$ is the waveguide cutoff frequency. The waveguide used is an $M$ size which, according to NARDA Catalog $\$ 20$, has a cutoff frequency of

$$
f_{c}=39.9 \mathrm{GHz} \text { or } \lambda_{c}=7.52 \mathrm{~mm} \text {. }
$$

We therefore found $\lambda_{0}=3.203 \mathrm{~mm}$, a value that correlates to the wavelength obtained with the wavemeter. 


\section{APPENDIX B}

\section{TEST SYSTEM AUTOMATION}

The purpose of this appendix is to outline the possible development of the described test system as a fully automatic system. The main advantage of such a system is the reduction in the time required for taking measurements. Due to the many tuning operations currently required, it may take up to one day to collect a complete set of data for one sample. Perhaps acceptable on a research level, this is entirely too time-consuming for use in a manufacturing environment. Perhaps equally as important as the time factor is the improvement in technique that would be accomplished by removing the human factor involved in testing. Ultimately, higher resolution and hence more precise data would result. As mentioned in Section 7.0, a major limitation in accuracy is the micrometer dial reading. This section describes a method that would allow the reading to be done quickly and more accurately.

The heart of the system would be a microprocessor that would sequence the operation of the hardware, collect and store the data, and perform necessary numerical calculations on the data. The single most important hardware interface unit would be an accurate stepping motor. The stepping motor would provide the rotational movement to the micrometer head. These micrometer heads would then supply the translation to lateral movement required by the frequency meter, standing wave indicator, and resonator back plate. A stepping motor could also be used for the mechanical tuning adjustment of the klystron. An electronically programmable klystron power supply also would be of great assistance in the setup: Figure $B^{-1}$ gives a block diagram of a suggested mechanical system. A keyboard is supplied for entering data such as film thickness, constants, and initial set points. A display is provided to give values of $Q$ and resistivity. Figure $B-2$ gives a block sequence diagram of implementation.

Setting initial conditions would require several steps and inputs. The first might bc to provide the reference voltage level to the power supply buffer circuit. The function of Detector 1 in conjunction with the buffer circuit is to supply a constant reference output from the klystron over a broad range of frequencies. This might require that the output level be examined, after the klystron was manually biased to oscillate, and a suitable value for the reference decided upon to give the necessary constant output over the required frequency range. In other words, by maintaining the klystron at a constant outpul level over a frequency range, the determination of the $Q$ value is simplified, and the expected value of $Q$ dictates the required range of frequencies needed. The buffer circuit would depend on the particular klystron power supply used, but its purpose would be to maintain the output at a given level determined as an initial condition. (An alternative approach would be to use yet another stepping motor to drive a precision attenuator located next to the isolater, allowing the klystron to vary. in power but compensating for it.) This technique suggests that a klystron of higher power would be useful in providing the necessary tuning range while maintaining the output above the noise level. If a Gunn diode were used as the source, it would be posslble to use a ferrite modulator to maintain a constant power output over a broad tuning range. 


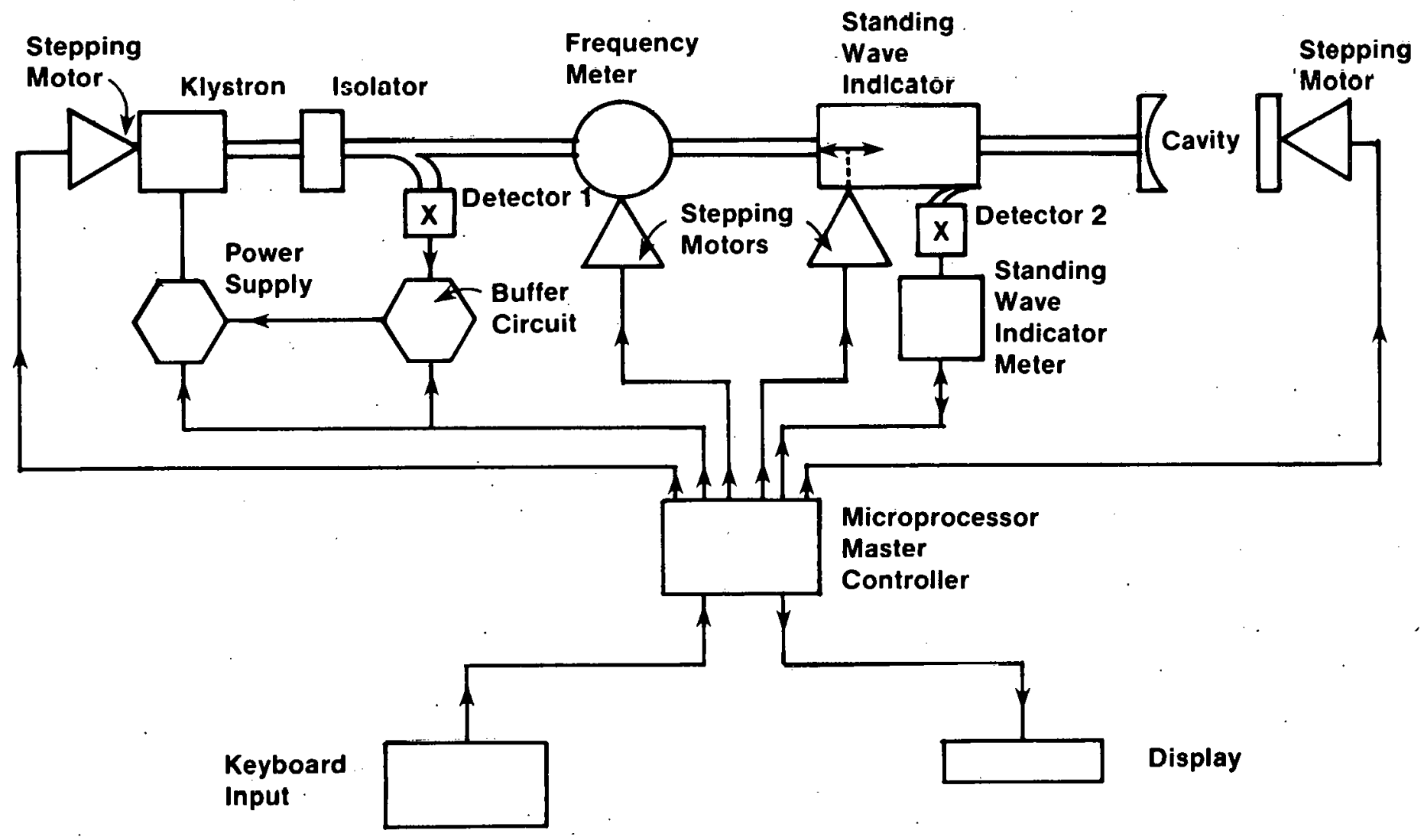

Figure B-1. Suggested Automated Setup 


Step $\quad \begin{gathered}\text { Execution } \\ \text { Time (min) }\end{gathered}$

Set initial

conditions

$\checkmark$

(I) Tune klystron to midpoint of

frequency

\begin{tabular}{|c|c|}
\hline $\begin{array}{l}\text { Tune SWI to } \\
\text { maximum }\end{array}$ & 0.01 \\
\hline $\begin{array}{c}\text { Tune cavity } \\
\text { to resonance } \\
Y\end{array}$ & 0.03 \\
\hline $\begin{array}{l}\text { Tune F.M. to } \\
\text { resonance, } \\
\text { record } x_{0}\end{array}$ & 0.1 \\
\hline Detune $F \cdot M$. & 0.01 \\
\hline $\begin{aligned} & \text { Set } \text { SWI meter } \\
& \text { to } 1\end{aligned}$ & 0.01 \\
\hline $\begin{array}{l}\text { Tune SWI to } \\
\text { minimum }\end{array}$ & 0.05 \\
\hline $\begin{array}{l}\text { Read meter } \\
\text { for VSWR, } r_{0}\end{array}$ & 0.04 \\
\hline $\begin{array}{l}\text { Calculate } \mathrm{r}_{\mathrm{o}} \\
\text { (half-power } \\
\text { VSWR) } \\
\text { A. }\end{array}$ & 0.02 \\
\hline
\end{tabular}

0.5

0.05

Step

A

$$
\begin{aligned}
& \text { offset klystron } \\
& \text { to } \mathrm{f}^{+} \text {at } \quad \mathrm{r} / \mathrm{2}
\end{aligned}
$$

Tune F.M. to

0.1

resonance.

$$
\text { Read }{ }^{x^{+}} \text {and } \quad 0.01
$$

detune

$$
\checkmark
$$

$$
\text { Offset klystron } \quad 0.05
$$$$
\text { to } \mathrm{f}^{-} \text {at } \mathrm{rl} / 2
$$

Tune F.M. to

0.1

resonance

$$
\text { Read } x^{-}
$$

0.01

0.01

(II)

$$
\begin{aligned}
& \text { Detune F.M. } \\
& \text { Calculate } \Omega_{0} \text {, } \\
& \text { store }
\end{aligned}
$$

0.01

Load sample

0.5

Input parameters

0.1

$\checkmark$

Repeat steps from

0.65

(I) to (II)

$\checkmark$

Calculate $Q_{S}$

0.02

Calculate $\rho$

0.02

Total time required

for measurement

Figure B-2 . Block Diagram of the Implementation of an Automatic Measurement System. SWI = standing wave indlcator;

F.M. = frequency meter. 
Other initial conditions required would be inputs regarding the frequency meter (F.M.) and resonator. The calculation of the frequency would require the input of the value of $q$ and the value of the distance between the frequency meter reflectors when the micrometer was set at zero. The value of $q$ would enable the calculation and movement by the stepping motor to the correct distance of reflector separation. Hence, if, as with our data, a q of 27 were determined, the stepping motor would advance the back reflector to a separation distance of around $8.9 \mathrm{~cm}$. This would be accomplished by knowing the initial reflector separation and the change of distance between reflectors per step. The initial condition of the resonator distance required to perform the calculation is also the initial displacement between the two end plates. This value, when added to the movement by the stepping motor, gives the value of $d$ required in the computation of $\rho$.

The next block in Fig. B-2 indicates the first functional step: the klystron would be set to a frequency in the middle of the constant output frequency band. This could be done by monitoring the output of Detector 2 while reversing the frequency stepping motor. The zero frequency occurs when the meter indicates a drop in power. (Note that to prevent false power drops it would be necessary to vary the cavity and F.M. stepping motors also to assure the drop is not due to resonance by either one.) By counting the number of steps taken in the reverse direction of frequency adjustment until the power dropped again, a midpoint could be determined and the klystron stepping motor would move to this position. Should the power supply be programmable externally, this same function could be accomplished by variation of the klystron reflector voltage modulation.

After klystron adjustment, the SWI would be driven to yield a maximum output on Detector 2. The resonator stepping motor would then be activated to tune to a resonant mode, the final result yielding the smallest value recorded by the SWI meter. The F.M. stepping motor would then be used to tune the F.M. to its resonance point. The distance between the F.M. reflector plates would be recorded for use in subsequent calculations.

Practical considerations on the characteristics of stepping motors are in order at this point. A very accurate motor, manufactured by Superior Electric, is capablc of 500 steps/revolution or 0.72 degrees/step. Commercial micrometer movements are designed to give a linear travel of $0.025 \mathrm{in./revo-}$ lulion. This corresponds to a direct connection between stepping motor and micrometer of 0.72-degree revolution; thus, one step yields a travel distance of $5.0 \times 10^{-5} \mathrm{in}$, or $1.27-\mu_{\mathrm{m}}$. In the visual reading measurements made, a micrometer reading was determined to the fifth significant digit, which corresponded to a reading of $0.254 \mu \mathrm{m}$. Therefore, resolution is worse in a direct conversion. The resolution becomes much better when a differential thread movement is set up. Distances of $0.0025 \mathrm{in}$./revolution are eas1ly obtained with this method, so that the stepping motor would have a resolution of $0.127 . \mu \mathrm{m} / \mathrm{step}$, which is a much better resolution than we obtained. Also, the accuracy is improved because the reading is not an extrapolation.

It is instructive to consider what kind of measurements could be made with the improved resolution. $\rho$ can be calculated using some of the recorded data. With a typical $Q_{0}$ of 7000 and $a d_{0}$ of $8.95 \mathrm{~cm}$, it can be calculated from $Q_{0}=$ $\mathrm{d}_{0} / 2\left(\mathrm{~d}_{0}-\mathrm{d}_{1}\right)$ that $\left(\mathrm{d}_{0}-\mathrm{d}_{1}\right)=6.3929 \times 10^{-4}$. (Notc that MAX $Q_{0}=352,360$ at 
$\left(d_{0}-d_{1}\right)=1.27 \times 10^{-5}$.) If now the sample is inserted and the variation in the frequency meter resonance is only one step, i.e.,.

$$
\left(d_{0}-d_{1}\right)=6.3929 \times 10^{-4}+1.27 \times 10^{-5},
$$

then we find

$$
Q_{\mathrm{S}}=6863 \text {. }
$$

For these values of $Q_{n}$ and $Q_{s}$ and a $30-\mu_{m}-t h i . c k$ sample of $C d S$ at 6 cm we can calculate the resistivity to be

$$
\rho=356 \Omega \mathrm{cm} \text {. }
$$

This is the maximum value of $\rho$ that can be obtained with this resolution.

After the location of the frequency meter resonance point was set, the frequency meter would be detuned by some specific amount. The SWI meter, electronically controlled, would be set to give a unity reading at the SWI maximum and the standing wave indicator stepping motor would be activated to locate the minimum in the standing wave pattern. The VSWR would be measured directly from the meter, and this value would be used in a calculation of the halfpower VSWR values with Eq. 6-3. Then the klystron frequency would be changed in one direction until the actual VSWR value matched the half-power value. At this point the frequency would be read. The klystron frequency then would be changed in the opposite direction to record the value on the other side of $f_{0}$ at which the half-power VSWR was reached. Once the frequency was read, a calculation of $Q_{0}$ could be made with the following equation:

$$
Q_{0}=\frac{f_{0}}{f^{+}-f^{-}} .
$$

The value would be displayed and stored; a command to load the sample would then follow. The sample parameters, thickness and $\varepsilon$, would be entered into the microprocessor and the above process repeated to calculate $Q_{S}$. An important addition would be a command limiting the available travel of the resonator back plate to assure measurement at the same $q$ number. From the determined value of $Q_{0}$ and the value of $Q_{s}$, along with the parameter inputs and the distance $d$, the value of resistivity would be determined and displayed.

This method is not the only way of automating the setup, nor is it necessarily the best way. It does, however, demonstrate a viable means of expediting the manual technique. Another method is to sweep the klystron frequency over a broad range. Analysis of the resultant response to the cavity allows determination of the half-power freqencies with a local beat oscillator. This method is described in Ref. 55 and would lend itself to an automated process. (It also would be possible to perform the measurements automatically at a variety of $q$ numbers and to average the final values over the different ranges.)

The numbers to the right of the flow diagram in Fig. B-2 indicate conservative estimates of the time required to accomplish each task. The final value of 
24.5 minutes is a substantial improvement over the 4 to 5 hours required to perform the measurement manually. 


\begin{tabular}{|c|c|c|}
\hline \begin{tabular}{|c|c|}
$\begin{array}{c}\text { Document Control } \\
\text { Page }\end{array}$ & $\begin{array}{c}\text { 1. SERI Report No. } \\
\mathrm{TR}-32-227\end{array}$ \\
\end{tabular} & 2. NTIS Accession No. & 3. Recipient's Accession No. \\
\hline \multicolumn{2}{|c|}{$\begin{array}{l}\text { 4. Title and Subtitle } \\
\text { Use of a Fabry-Perot Resonator } \\
\text { at Millimeter Wave Frequencies in the } \\
\text { Determination of Thin-Film Resistivities }\end{array}$} & $\begin{array}{l}\text { 5. Publication Date } \\
\text { August } 1979 \\
6 .\end{array}$ \\
\hline \multicolumn{2}{|l|}{ 7. Author(s) } & 8. Performing Organization Rept. No. \\
\hline \multicolumn{2}{|c|}{$\begin{array}{l}\text { 9. Performing Organization Name and Address } \\
\text { Solar Energy Research Institute/DOE } \\
\text { 1536 Cole Boulevard } \\
\text { Golden, Colorado } 80401\end{array}$} & $\begin{array}{l}\text { 10. Project/TaskiWork Unit No. } \\
\text { Task \#⿰氵3221.10 } \\
\text { 11. Contract (C) or Grant (G) No. } \\
\text { (C) }\end{array}$ \\
\hline \multicolumn{2}{|l|}{ 12. Sponsoring Organization Name and Address } & $\begin{array}{l}\text { 13. Type of Report \& Period Covered } \\
\text { Technical Report } \\
14 .\end{array}$ \\
\hline \multicolumn{3}{|l|}{ 15. Supplementary Notes } \\
\hline \multicolumn{3}{|c|}{$\begin{array}{l}\text { 16. Abstract (Limit: } 200 \text { words) } \\
\text { We have developed a novel contact-free method of measuring resistivity of thin } \\
\text { semiconducting films on highly conductive substrates. The material structure } \\
\text { studied is commonly encountered in thin-film solar cell development. This report } \\
\text { discusses in detail the microwave technique that involves using a semiconfocal } \\
\text { Fabry-Perot cavity at a wavelength of } 3 \mathrm{~mm} \text {. The sample consists of a thin film of } \\
\text { CdS on a brass substrate and is mounted on the flat reflector of the cavity. Using } \\
\text { field perturbation methods, an expression is derived that relates the film resis-. } \\
\text { tivity to the cavity quality factor Q. The cavity quality factor is an easily } \\
\text { measured parameter and, hy comparing measurements of Q with and without the sample } \\
\text { mounted, an accurate measure of the resistivity is obtained. Accuracy of measure- } \\
\text { ments and necessary sample constraints are discussed in detail. } \\
\text { Three samples were measured of Cds on brass substrates spanning an order of mag- } \\
\text { nitude in resistivicy differeirce. The recults of the method described in this } \\
\text { report agree with those of another method that involves current voltage measure- } \\
\text { ment after application of a metallic contact. Unlike the latter method, however, } \\
\text { the new technique provides a nondestructive way of measuring the resistivity of } \\
\text { semiconductor films on conducting substrates and is amenable to automation. }\end{array}$} \\
\hline \multirow{2}{*}{\multicolumn{3}{|c|}{$\begin{array}{l}\text { 17. Document Analysis } \\
\text { a. Descriptors Thin Films; Electrical Conductiyity; Measuring Methods; Comparative } \\
\text { Eyaluations; Solar Cells; Cadmium Sulfide Solar Cells; Cadmium Sulfides; Brass; } \\
\text { Substrates; Microwave Spectroscopy; Nondestructive Testing } \\
\text { b.Identifiers/Open-Ended Terms }\end{array}$}} \\
\hline & & \\
\hline \multirow{2}{*}{$\begin{array}{l}\text { 18. Availability Statement } \\
\text { NTIS, U.S. Dept. of Commerce } \\
5285 \text { Port Rnya } 1 \text { Rd. } \\
\text { Springfield, VA } 22161\end{array}$} & & $\begin{array}{r}\text { 14. No. of Pages } \\
80\end{array}$ \\
\hline & & $\begin{array}{r}\text { 20. Price } \\
\\
\end{array} \$ 6.00$ \\
\hline
\end{tabular}

